\title{
EDUCAÇÃO:
}

\section{PROCESSO CONTÍNUO DE}

\section{DESENVOLVIMENTO}

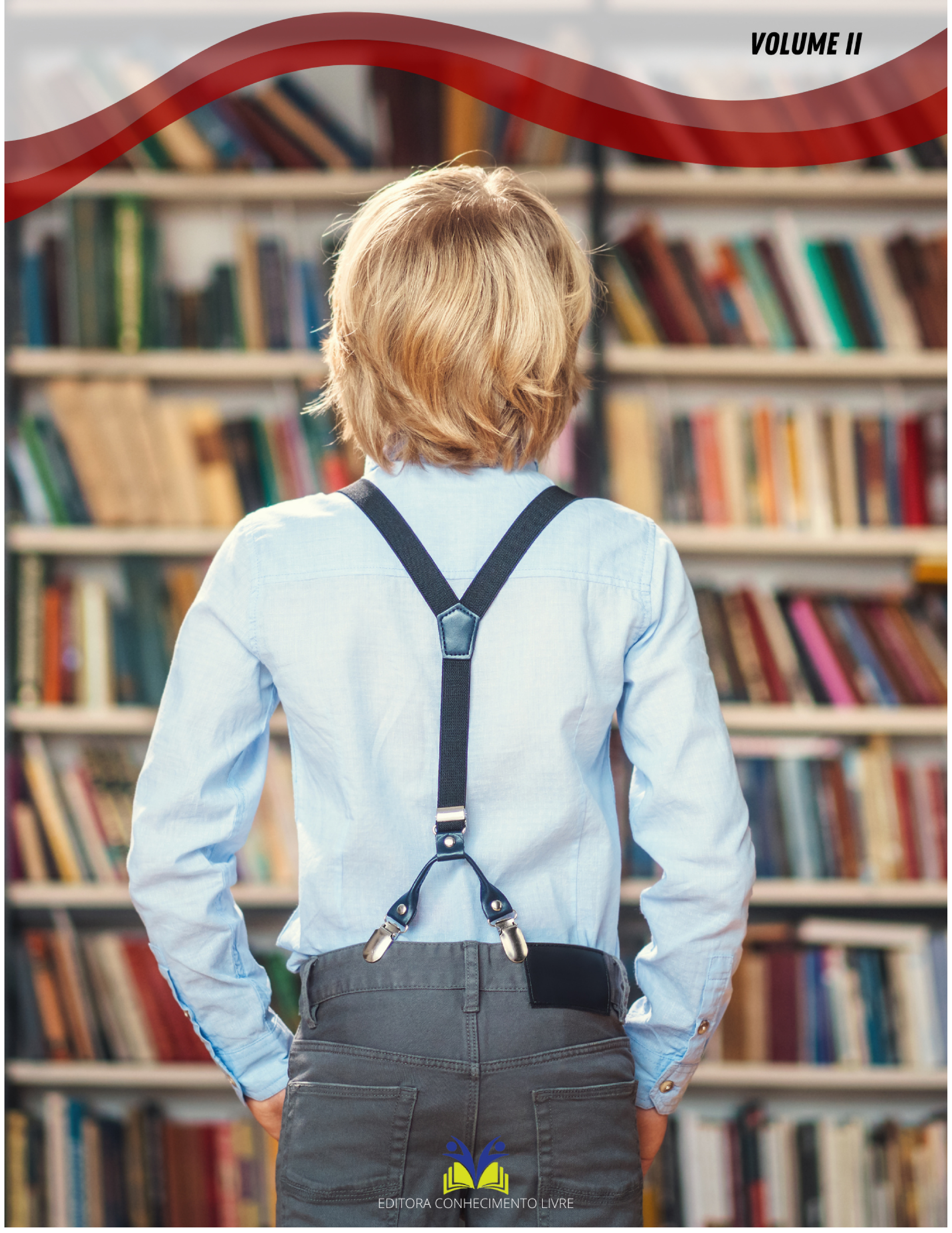


Frederico Celestino Barbosa

Educação: processo contínuo de desenvolvimento

$1^{\text {a }}$ ed.

Piracanjuba-GO

Editora Conhecimento Livre

Piracanjuba-GO 
$1^{\mathrm{a}} \mathrm{ed}$

\section{Dados Internacionais de Catalogação na Publicação (CIP)}

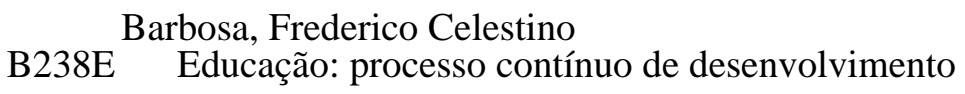

/ Frederico Celestino Barbosa. - Piracanjuba-GO

Editora Conhecimento Livre, 2021

48 f.: il

DOI: $10.37423 / 2021$.edcl 362

ISBN: 978-65-89955-83-2

Modo de acesso: World Wide Web

Incluir Bibliografia

1. ensino 2. pesquisa 3. extensão I. Barbosa, Frederico Celestino II. Título

CDU: 370

https://doi.org/10.37423/2021.edc1362

O conteúdo dos artigos e sua correção ortográfica são de responsabilidade exclusiva dos seus respectivos autores. 


\title{
EDITORA CONHECIMENTO LIVRE
}

\section{Corpo Editorial}

\author{
Dr. João Luís Ribeiro Ulhôa \\ Dra. Eyde Cristianne Saraiva-Bonatto \\ Dr. Anderson Reis de Sousa \\ MSc. Frederico Celestino Barbosa \\ MSc. Carlos Eduardo de Oliveira Gontijo
}

$\underline{\text { MSc. Plínio Ferreira Pires }}$

Editora Conhecimento Livre

Piracanjuba-GO 


\section{SUMÁRIO}

CAPÍTULO 1 5 EDUCAÇÃO FINANCEIRA PARA JOVENS E ADULTOS: CONSTRUINDO UM CADERNO DE RECEITAS

ARLAM DIELCIO PONTES DA SILVA

DOI 10.37423/211104974

CAPÍTULO 2

A ESCOLA NA PERSPECTIVA INCLUSIVA E PESSOAS COM SURDOCEGUEIRA: O

ATENDIMENTO EDUCACIONAL ESPECIALIZADO COMO SUBSÍDIO PARA INCLUSÃO NA ESCOLA COMUM

Bernardo Lima de Sena

DOI 10.37423/211104994

\section{CAPÍTULO 3}

AS TECNOLOGIAS COMO APORTE PARA O PROCESSO DE ENSINO APRENDIZAGEM: UMA REVISÃO SISTEMÁTICA DA LITERATURA

Alexandre Junior de Souza Menezes

Edson Ferreira da Silva

Gabriel Luiz Nascimento Fioramonte

Helder Ferreira da Silva

Letícia Lima Nogueira Coelho

Nelson Pereira da Costa Filho

Rosival Jacques Molina

Hellen de Campos Madia

DOI 10.37423/211105004

\section{CAPÍTULO 4}

ÁGUA E MEIO AMBIENTE NO ENSINO DE QUÍMICA: AS DIFICULDADES EM

CONTEXTUALIZAR A TEORIA COM O COTIDIANO

Edson Valente Chaves

Márcia Rebeca Silva de Oliveira

Isabele Fernanda Silva de Moraes

DOI 10.37423/211105035 


\section{Capítulo 1}

doi $10.37423 / 211104974$

\section{EDUCAÇÃO FINANCEIRA PARA JOVENS E ADULTOS: CONSTRUINDO UM CADERNO DE RECEITAS}

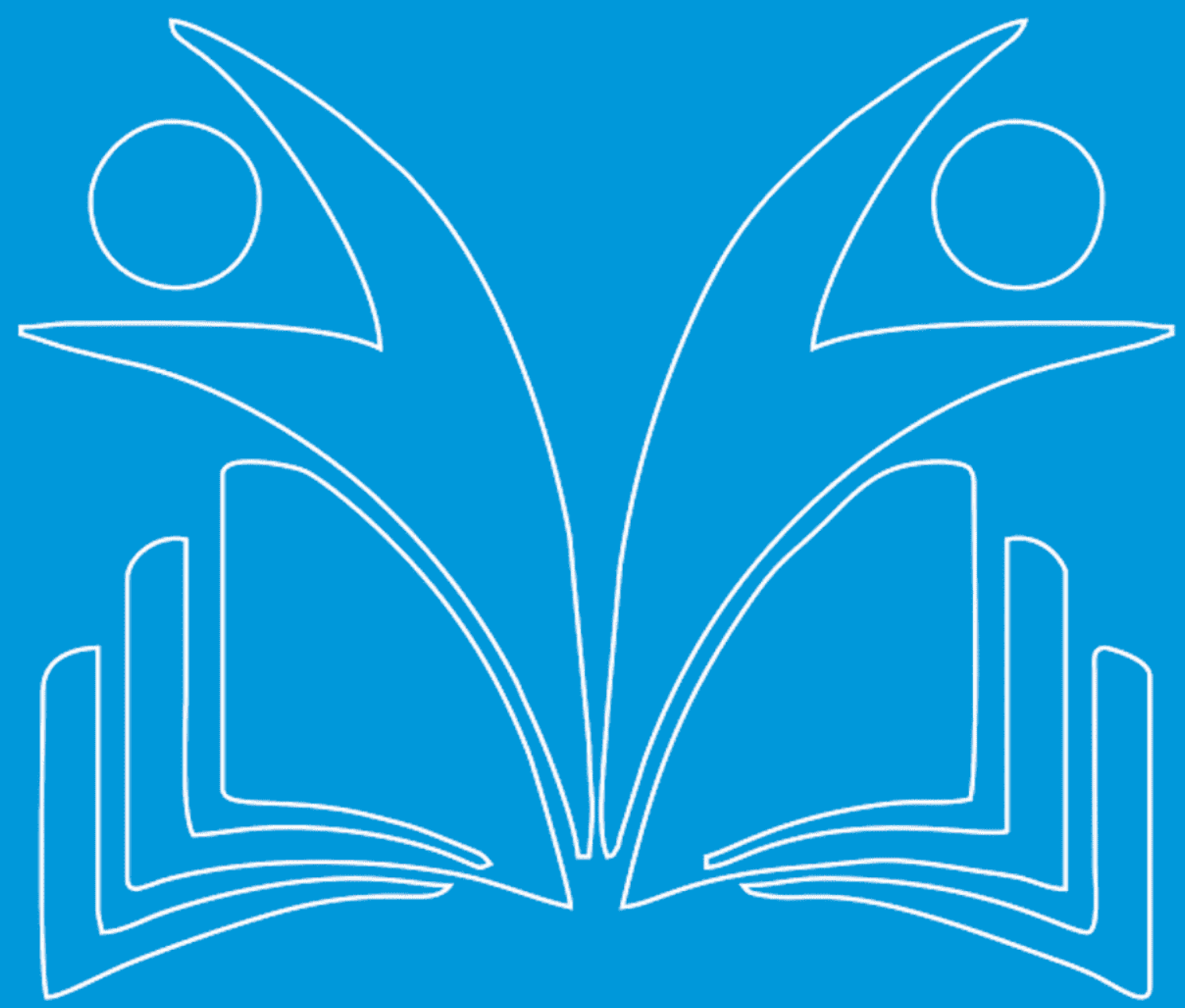


Resumo: $O$ atual cenário econômico do Brasil, nos coloca em situação de alerta para com nossas finanças. No entanto, a necessidade de planejamento financeiro é uma realidade que se faz presente na vida da maioria dos brasileiros, e não apenas no momento de crise. A crise tão destacada pelas mídias, apenas reforça a importância de levarmos para a sala de aula, uma Educação voltada para o aspecto financeiro dos indivíduos. Assim, esta pesquisa apresenta resultados de uma sequência de atividade desenvolvidas com estudantes da Educação de Jovens e Adultos (EJA), tendo como principais envolvidos, bolsistas do Programa de Bolsas de Iniciação à Docência (PIBID- financiado pela CAPES), no ano de 2015. Levantada a importância de inserirmos esta temática no ensino da Educação Básica, nos propusemos a trabalhar com a Educação Financeira numa turma de 2a Fase da EJA. Temos como objetivos: identificar o perfil da turma; desenvolver estratégias para educar financeiramente esses estudantes da EJA, por meio de reflexões e discussões interdisciplinar e criar um caderno de receitas. Como resultados, apresentamos uma turma com perfil dividido entre pessoas empregadas, autônomas, desempregados e que não possuem renda. Houveram encontros para discussão e reflexão da temática, que auxiliou os estudantes a desenvolverem um senso de criticidade, permitindo que eles expusessem suas experiências durante as reflexões. O caderno de receitas, apesar de não ter saído como planejado, se destaca como sendo uma ferramenta para o ensino financeiro que se preocupa prioritariamente com as acepções que serão construídas pelos estudantes e levadas para seu cotidiano.

Palavras-chave: Educação Financeira; Educação de Jovens e Adultos, Ensino Interdisciplinar. 


\section{INTRODUÇÃO}

As turmas de Educação de Jovens e Adultos (EJA), são formadas por um público diferenciado, considerando as primeiras fases desta modalidade, encontramos um ambiente cujas experiências dos estudantes são muito diversas, ou seja, temos estudantes na idade da adolescência, de jovens, adultos e idosos, podendo facilmente ser encontradas turmas cujos estudantes tenham por exemplo, entre 15 e 75 anos. Esse destaque contribui para diversidade, uma vez que encontramos pessoas com diferentes profissões, faixa etária, situação e experiências de vida.

Segundo Soek (2009), as turmas de EJA devem ter como objetivo "formar cidadãos capazes de lutar por seus direitos e de se apropriar dos conhecimentos mediados pela escola para se aprimorar no mundo do trabalho e na prática social" (p. 29). Assim sendo, cabe a escola proporcionar uma Educação pensada especificamente para este público, satisfazendo as necessidades desses sujeitos, conforme destaca Freire (1996, p. 52) ao afirmar que o papel do educador não é meramente o de transferir seus conhecimentos e/ou os conteúdos a serem estudados, isso porque a produção de conhecimentos acontece de maneira diferente em cada indivíduo, para tanto, depende do educador, desenvolver maneiras e estratégias, e dar "forma ou alma" ao que se apresenta como desconhecido ou incompreensível.

Ainda, por apresentarem uma especificidade reconhecida por estudiosos da área, no que se refere às experiências de vida que possuem, é preciso oportunizar a aprendizagem a esses estudantes, levando em consideração esse diferencial que é também uma das exigências legais, pois, de acordo com a LDB (Lei de Diretrizes e Bases da Educação, no 9394/96) art. 37, parágrafo 1ㅇ, “...os sistemas de ensino devem oferecer oportunidades educacionais apropriadas, considerando as características do alunado, seus interesses, condições de vida e de trabalho". Nesse sentido é dever do Estado oferecer subsídios para que este público tenha acesso ao ambiente de ensino, de modo que se procure ao máximo voltar a atenção diferenciada para as suas necessidades enquanto jovens e adultos em sala de aula fora da faixa etária.

Movimentações financeiras estão presentes em nosso cotidiano de forma naturalizada, ou seja, fazemos uso de dinheiro e valores diariamente, várias vezes ao dia, e se quer percebemos ou pouco temos consciência deste ato. Mesmo sendo uma ação humana que é incorporada ainda quando crianças, pouco desenvolvemos o hábito de refletir e estudar sobre. Encontrando uma lacuna entre o que aprendemos nas escolas e a razão prática que damos a essa aprendizagem no decorrer da vida. 
Percebemos que na sociedade como um todo é escassa a preocupação em educar financeiramente os sujeitos, as poucas informações oferecidas por bancos e algumas empresas não são suficientes para atingir a um contingente considerável da população, além de serem conteúdos produzidos por pessoas que visam lucro, não necessariamente o bem-estar financeiro de seus clientes.

Trazer para o ambiente educacional a possibilidade de um trabalho pedagógico voltado para a Educação Financeira, possibilita, de acordo com Campos (2012, p.24) "atingir diversos segmentos da população, tendo em vista a busca da universalização da Educação Básica. É importante ainda considerar que os estudantes poderão levar questões para serem discutidas em seus lares", assim, seriam ampliados o alcance da proposta para um número maior de sujeitos receptores de uma formação financeira, incialmente feita com um público de estudantes, os quais, no caso da EJA, podem levar seu aprendizado para, além da família, seu ciclo de amigos e colegas de trabalho, uma vez que, em maioria, já estão inseridos no mercado de trabalho.

Para tanto, pensar numa Educação Financeira, requer que tenhamos a sensibilidade de perceber que esta temática não é dependente exclusivamente das aulas de Matemática, uma vez que além da importância de aprendizagem com cálculos, o estudante precisa ser incorporado num cenário de reflexão acerca de suas ações enquanto consumidor.

Assim, concordamos com Saito (2007), que discute as transformações e complexidade que o Plano Real trouxe para a não familiarização das pessoas com o planejamento a longo prazo, fato esse que podemos destacar como um dos principais impedimentos para uma conscientização financeira das pessoas, uma vez que junto com o Plano Real, não veio uma estratégia de formar as pessoas para se adequarem a essa nova moeda. Entramos em acordo ainda, nas discussões de Souza \& Torralvo (2008), que estudam o crescente acesso ao crédito, o que se apresenta como facilidade para compradores e vendedores, mas que pode se tornar um problema se mal administrado. Também com Araújo (2009), que levanta discussões acerca da influência que a mídia e as propagandas de marketing fazem nas pessoas, de modo a considerar ainda a relação entre os sujeitos consumidores e o meio ambiente, pois existe um ciclo de consumo-desperdício-lixo-consumo.

Diante do exposto, destacamos a importância de trabalhar a temática numa perspectiva que vislumbre a emancipação dos sujeitos, ou seja, que o foco do ensino, seja o estudante e a sua realidade. Temos como principais objetivos deste trabalho: Identificar o perfil da turma de 2a Fase da EJA, Desenvolver estratégias para educar financeiramente estudantes da EJA, por meio de reflexões e discussões interdisciplinar; Criar um caderno de receitas. 


\section{METODOLOGIA}

A partir desta proposta, caracterizamos nosso estudo como sendo de natureza, uma pesquisa-ação, a qual segundo Xavier (2013) “é aquela em que o pesquisador faz intervenções diretas na realidade social que se apresenta com algum problema. Ele interage de forma intensa com os sujeitos pesquisados e com a realidade que o cerca (p. 47)". Assim sendo, esse tipo de pesquisa permite que o pesquisador faça intervenções na realidade dos sujeitos pesquisados. Articulada, teremos conversas informais, questionários e observações.

Para tanto, também fizemos uso do método qualitativo que nos permite qualificar os resultados obtidos na intervenção. Considerando a intervenção, nos planejamos de acordo com as seguintes etapas:

1a Etapa: Questionário e conversas informais para conhecer o perfil da turma;

2a Etapas: Dinâmicas e discussões com a temática (consumo, alimentação saudável, sustentabilidade, planejamento financeiro, etc.);

3a Etapa: Pesquisa de receitas de baixo custo;

4a Etapa: Criar o caderno de receitas.

\section{RESULTADOS E DISCUSSÕES}

A intervenção ocorreu numa escola municipal do interior de Pernambuco, a turma possui 31 pessoas matriculadas, no entanto, contamos com a participação de uma média de 8 a 10 estudantes, da 2a Fase da Educação de Jovens e Adultos, por encontro. A faixa etária desta turma é de 14 a 62 anos de idade. No quadro abaixo, encontramos dados referente as profissões e média salarial da turma, divididos por sexo, informados pelos estudantes.

\begin{tabular}{|c|c|}
\hline \multicolumn{2}{|c|}{ HOMEM } \\
\hline PROFISSÃO & SALÁRIO \\
\hline 1 Desempregado & $\mathrm{R} \$ \quad 0,00$ \\
\hline 1 Pedreiro & $\mathrm{R} \$ 900,00$ \\
\hline 1 Aposentados & $\mathrm{R} \$ 830,00$ \\
\hline \multicolumn{2}{|c|}{ MULHER } \\
\hline PROFISSÃO & SALÁRIO \\
\hline 2 Manicure e cabelereira & $\mathrm{R} \$ 1050,00$ \\
\hline 2 Dona de Casa & $\mathrm{R} \$$ Não possui renda \\
\hline 3 Diaristas & $\mathrm{R} \$ 700,00$ \\
\hline
\end{tabular}

Tabela 01: Perfil econômico da turma. 
Encontramos no perfil econômico da turma, pessoas que não possuem renda fixa, para tanto, educalas financeiramente, requer um cuidado extra, tendo em vista que no caso das donas de casa, por exemplo, elas mesmo sem terem renda, são as principais responsáveis por gastos como, supermercado, feira, e controle de outras contas fixas de uma residência. Em conversas com essas mulheres, percebemos em suas falas, a presença de uma preocupação voltada para a administração das finanças.

Nas etapas 2 e 3, que foram divididas para ocorrer em dois encontros, realizamos discussões pautadas em questões sociais e ambientais, que se fazem necessárias para uma Educação Financeira, uma vez que são temas que fazem parte do cotidiano social. Os dois encontros tiveram um planejamento similar, eram divididos em quatro momentos: 1- Dinâmica de introdução do assunto do encontro; 2Apresentação de vídeo para mobilizar as discussões; 3- Discussões e reflexões; 4- Proposta de pesquisa

\begin{tabular}{|c|c|c|c|}
\hline \multicolumn{2}{|c|}{ ENCONTRO 01} & \multicolumn{2}{|c|}{ ENCONTRO 02} \\
\hline $1^{\circ} \mathrm{MOMENTO}$ & $-x-$ & $1^{\circ} \mathrm{MOMENTO}$ & $\begin{array}{l}\text { Dinâmica do Consumo: } \\
\\
\text { Entregamos um valor } \\
\text { diferente, com cédulas } \\
\text { faltas, em envelopes } \\
\text { lacrados a cada estudante. } \\
\text { E dispomos diferentes } \\
\text { produtos na sala. Cada um } \\
\text { poderia comprar o que } \\
\text { quisesse, depois justificaria } \\
\text { o que comprou e o porquê } \\
\text { de ter comprado aquilo. } \\
\text { Trazendo para esse } \\
\text { momento, as suas } \\
\text { observações referente a } \\
\text { pesquisa sugerida no } \\
\text { encontro anterior. }\end{array}$ \\
\hline $2^{\circ} \mathrm{MOMENTO}$ & $\begin{array}{l}\text { Apresentação de vídeo } \\
\text { sobre alimentação, } \\
\text { desperdício de } \\
\text { alimentos e } \\
\text { sustentabilidade. }\end{array}$ & $2^{\circ} \mathrm{MOMENTO}$ & $\begin{array}{l}\text { Apresentação de vídeo } \\
\text { sobre consumo e } \\
\text { propagandas. }\end{array}$ \\
\hline $3^{\circ} \mathrm{MOMENTO}$ & $\begin{array}{c}\text { Discussão, que levanta } \\
\text { questões referente ao } \\
\text { excesso de alimentos } \\
\text { que desperdiçamos, por } \\
\text { não haver um } \\
\text { planejamento na hora }\end{array}$ & $3^{\circ} \mathrm{MOMENTO}$ & $\begin{array}{l}\text { Discussão acerca do } \\
\text { vídeo, trazendo } \\
\text { questões referente ao } \\
\text { consumo consciente, a } \\
\text { necessidade de um } \\
\text { planejamento }\end{array}$ \\
\hline
\end{tabular}




\begin{tabular}{|c|c|c|c|}
\hline & $\begin{array}{l}\text { da compra. Os impactos } \\
\text { que esse ciclo de } \\
\text { desperdício causa ao } \\
\text { meio ambiente, e os } \\
\text { resultados disso a } \\
\text { médio e longo prazo no } \\
\text { bolso do consumidor. }\end{array}$ & & $\begin{array}{l}\text { financeiro, além de } \\
\text { exemplos de } \\
\text { endividamento que } \\
\text { podem comprometer a } \\
\text { renda familiar, e } \\
\text { prejudicar consumos } \\
\text { de primeira } \\
\text { necessidade, como } \\
\text { alimentos e moradia. }\end{array}$ \\
\hline $4^{\circ}$ MOMENTO & $\begin{array}{l}\text { Proposta de pesquisa: } \\
\text { solicitar aos estudantes } \\
\text { que durante a semana, } \\
\text { observem os panfletos } \\
\text { que recebem, e as } \\
\text { propagandas na TV, } \\
\text { que incentivam o } \\
\text { consumo de produtos. }\end{array}$ & $4^{\circ} \mathrm{MOMENTO}$ & $\begin{array}{c}\text { Proposta de pesquisa: } \\
\text { Cada estudante deverá } \\
\text { pensar, ou pesquisar, } \\
\text { uma receita que seja } \\
\text { de valor acessível a } \\
\text { todos, ou seja, com } \\
\text { ingredientes baratos. } \\
\text { Para que no próximo } \\
\text { encontro, possamos } \\
\text { construir o nosso } \\
\text { caderno de receitas. } \\
\text { Sugerido também, que } \\
\text { se possível tragam os } \\
\text { preços dos } \\
\text { ingredientes. }\end{array}$ \\
\hline
\end{tabular}

Tabela 02: Apresentação dos momentos de cada encontro, separado para as discussões e reflexões.

Expomos, brevemente como ocorreram os encontros com a turma. Como fruto do último encontro, obtivemos resposta de 8 estudantes, os quais levaram as receitas conforme solicitadas. Nesse último encontro, coletamos as receitas, e pelo fato de a escola não dispor de laboratório de informática, que seria de grande importância no processo de construção da autonomia informacional desses estudantes, optamos por montar o caderno em coletivo, com um notebook conectado à rede e a um Datashow. Assim, conseguimos o resultado conforme as imagens abaixo. 


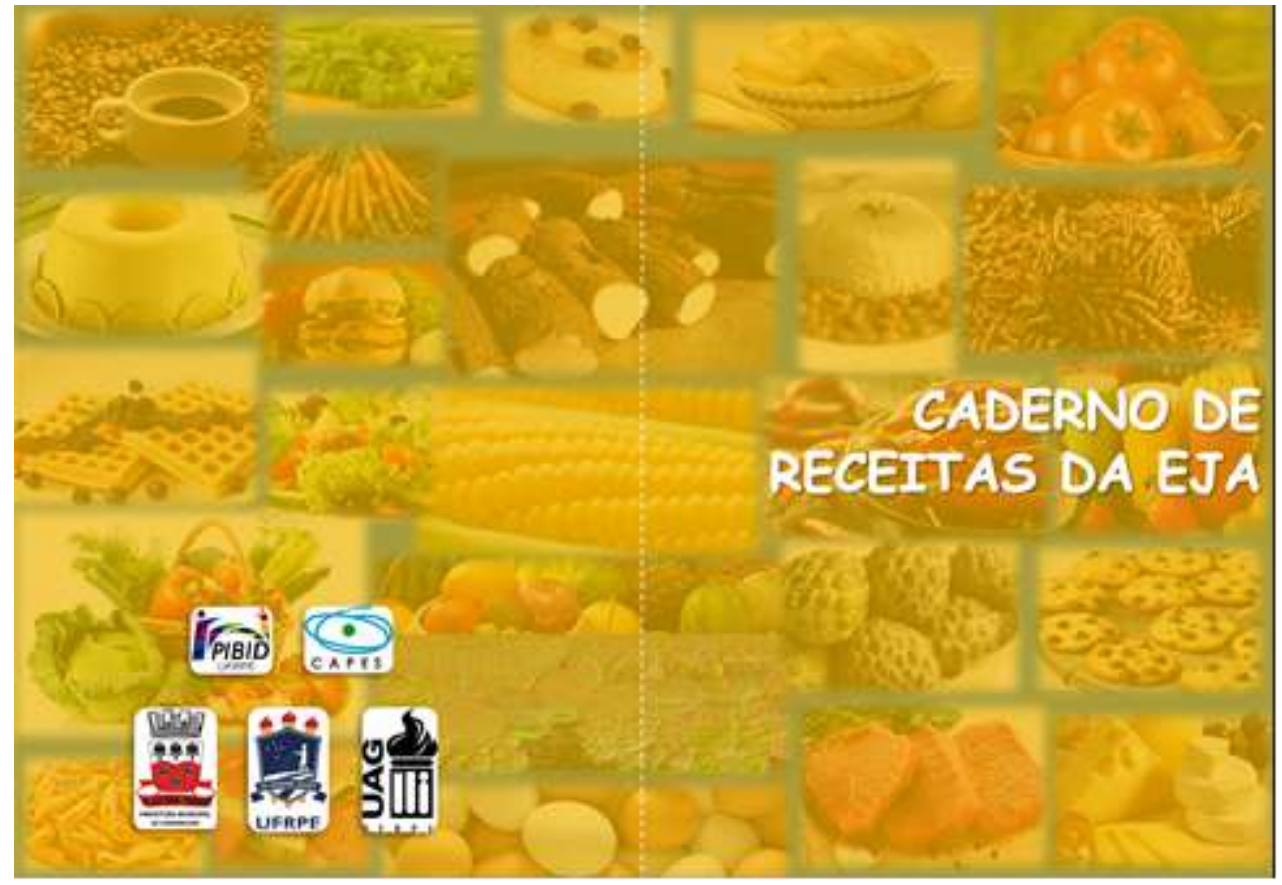

Imagem 01: Capa frontal e traseira do caderno.

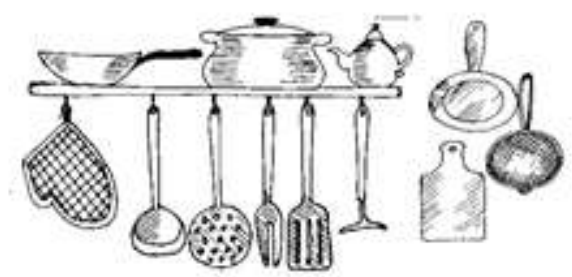

PIRÃO DE CARNE

Ingrectiontes:

I Pimentle

t sebola

1 bonate

3 Hatacinehas

1 Chuchu.

$1 / 2$ espolbs

1 igy de came de boi com nse

Modo de posparo:

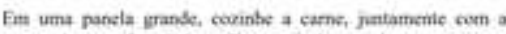

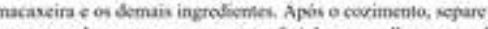

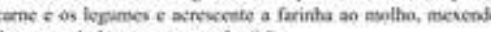
Aevagar até chejar ao ponto de purto.

J.J. dasave

\section{BRIGADEIRO DE MILHO}

\section{Ingrodicates:}

02 caixas de hite icodonsibo

01 lata de millo vercle:

03 eoltheres (sopu) de ascicat

O1 colter (sopou) de canels em poi

M) collher (uppo) de margarita

\section{Sodo de erevare:}

Pase o millo no biquidificalor e reweres leve as fopo baixo a mistura do lewe condensubs, a mameiga co milho ji totido, mexa e eumedo estiver devgralando da panels (preto de brigadeiro)

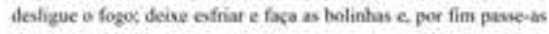
na miatura bo acúf te com a cancia.

J. A. de Noronhat

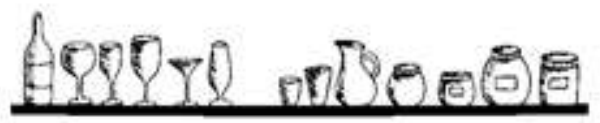

Imagem 02: Exemplo de duas páginas do Caderno de Receitas sugeridas pelos estudantes.

As imagens apresentadas correspondem ao resultado final do caderno de receitas. Observamos que no caderno, não consta os preços dos ingredientes, conforme foi sugerido no início da proposta. Isso deve-se ao fato de que apenas dois estudantes apresnteram os valores, e junto aos demais, foi decidido não colocar, para que o caderno seguisse uma padronização. Mesmo com a ausência dos valores, podemos destacar o resultado desta atividade, como sendo positiva, uma vez que se 
considerado todo o percurso da proposta, conseguimos alcançar os objetivos de dar início a uma estratrégia de Educação Financeira, que permitiu a esses estudantes, uma reflexão maior e um planejamento diante de suas finanças.

\section{CONCLUSÃO}

Conforme os dados apresentados, podemos reafirmar a importância de uma Educação Financeira para jovens e adultos, uma vez que este público lida diariamente com recursos financeiros e tomada de decisões. Verificamos aspectos positivos com este trabalho, ao observarmos na fala dos estudantes, a presença de um discurso mais cauteloso no que se refere ao uso de suas finanças pessoais. Podemos afirmar ainda, que tal proposta, auxilia na emancipação dos estudantes envolvidos, se considerada as limitações que a falta de um olhar reflexivo faz, ou seja, os estudantes envolvidos tiveram a oportunidade de conscientizar-se de seus gastos, percebendo quando realmente há a necessidade de comprar, ou se não passa de um desejo em possuir determinado produto, ainda podendo considerar fatores externos a sua decisão final, como por exemplo, se as propagandas influenciam ou não. Esta temática, apresenta ainda um ponto positivo a ser destacado, que é o fato de que ela permite ao professor, a abertura de poder trabalhar de maneira interdisciplinar, fazendo uso da Educação Financeira como norte para entrar em discussões em parceria com outras áreas do conhecimento. 


\section{REFERÊNCIAS}

ARAÚJO, Regina Magna Bonifácio de. Alfabetização econômica: compromisso social na educação das crianças. São Bernardo do Campo: Universidade Metodista de São Paulo, 2009.

CAMPOS, Marcelo Bergamini. Educação financeira na matemática do ensino fundamental: uma análise da produção de significados. 2012, 179p. Dissertação de Mestrado. Universidade Federal de Juiz de Fora, Juiz de Fora.

BRASIL. Lei de diretrizes e bases da educação nacional n9394/96. Brasília: Ministério da Educação e Cultura, 1996.

FREIRE, Paulo. Pedagogia da autonomia: saberes necessários à prática educativa. São Paulo: Paz e Terra, 1996.

SAITO, Andre Taue. Uma contribuição ao desenvolvimento da educação em finanças pessoais no Brasil. 2007, 152p. Dissertação de Mestrado. Universidade de São Paulo, São Paulo.

SOEK, Ana Maria. Mediação pedagógica na alfabetização de jovens e adultos. Curitiba: Positivo, 2009.

SOUZA, Almir Ferreira de; TORRALVO, Caio Fragata. Aprenda a administrar o próprio dinheiro: coloque em prática o planejamento financeiro pessoal e viva com mais liberdade. São Paulo: Saraiva, 2008.

XAVIER, Antonio Carlos. Como fazer e apresentar trabalhos cientificos em eventos acadêmicos: ciências humanas e sociais aplicadas. Recife: RÊSPEL, 2010. 


\section{Capítulo 2}

doi $10.37423 / 211104994$

\section{A ESCOLA NA PERSPECTIVA INCLUSIVA E PESSOAS COM SURDOCEGUEIRA: O} ATENDIMENTO EDUCACIONAL ESPECIALIZADO COMO SUBSÍDIO PARA INCLUSÃO NA ESCOLA COMUM

Bernardo Lima de Sena

Centro Universitário do Rio Grande do NorteUNI-RN

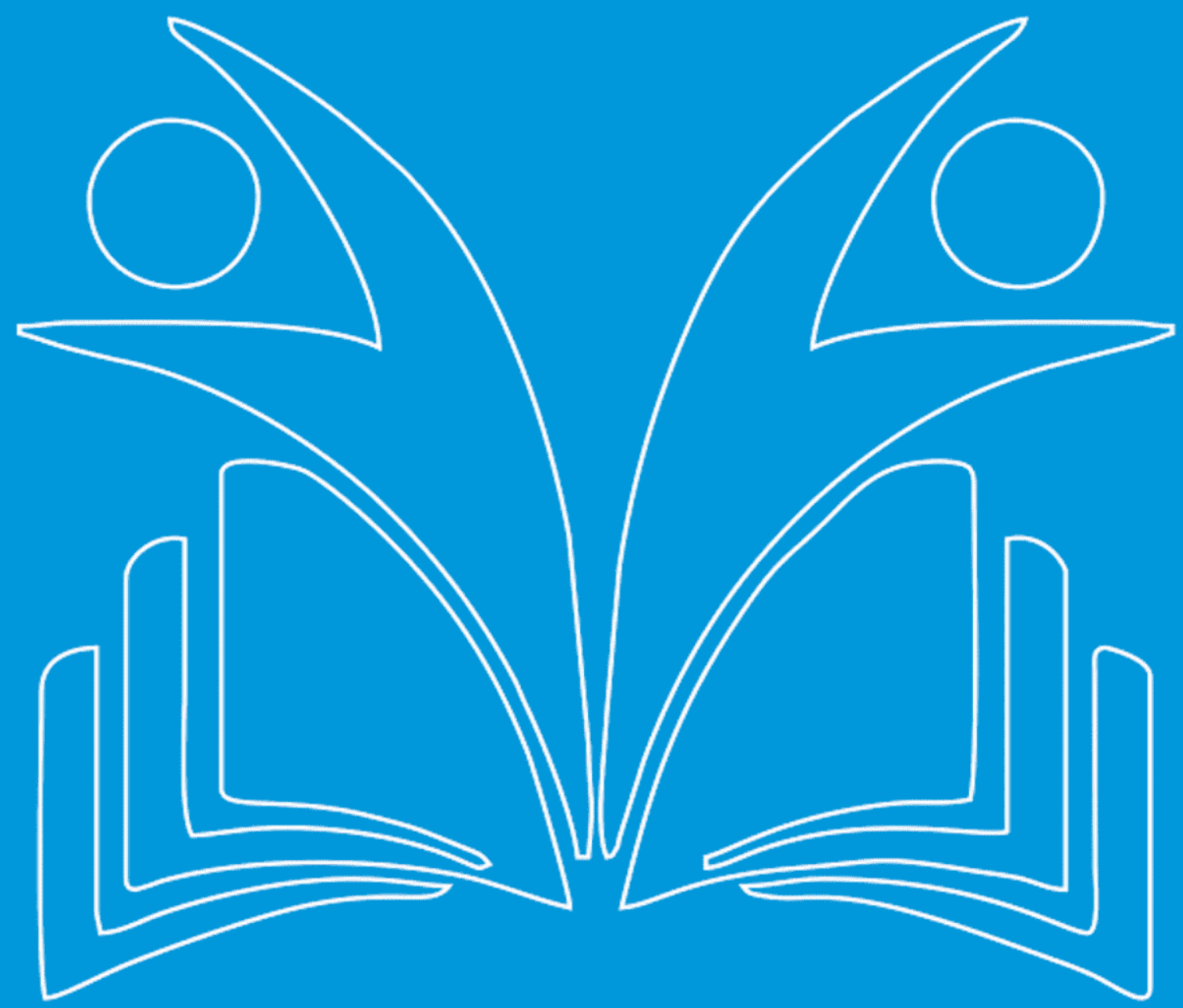




\section{INTRODUÇÃO.}

Este trabalho se alvitra e tem por objetivo prestar algumas ideias, a partir de uma revisão da literatura sobre o tema da surdocegueira, que poderão contribuir com para a inclusão de pessoas com essa deficiência no espaço da escola comum. Vale ressaltar que a inclusão rompe com os protótipos que alimentam o tradicionalismo das escolas, contestando os sistemas educacionais em seus embasamentos. Ela passa a discutir a definição de padrões ideais, a normalização de perfis específicos de alunos e a seleção dos eleitos para frequentar a escola (ROPOLI, 2010).

Os espaços escolares inclusivos são abalizados numa compreensão de identidade e diferenças, em que as relações entre dois não se dispõem em torno de oposições binárias (normal/especial), não se elegendo uma identidade como singular em relação às demais. Em espaços escolares de exclusão, a identidade singular é tida como a preferencial, a correta, a natural, generalizada e positiva em relação às demais, sua definição provém do processo pelo qual o poder se manifesta na escola, elegendo uma identidade única, por meio da qual as outras identidades são consideradas e hierarquizadas (ROPOLI et al, 2010).

A educação inclusiva questiona a artificialidade de identidades normais e entende as diferenças como resultado de multiplicidade, e não da diversidade, como comumente se proclama. Para Silva, citado por Rapoli et al(2010), a diferença vem do múltiplo e não do diverso. O autor traz que, assim como acontece na aritmética, o múltiplo é sempre uma ação.

E enquanto a DIVERSIDADE é estática, estéril, a MULTIPLICIDADE é produtiva, uma máquina de produzir diferenças. Ou seja, enquanto a diversidade se limita ao que já existe, a multiplicidade se prolifera. A multiplicidade incita a diferença que se renuncia a se liquefazer com o idêntico.

No desejo de assegurar a unidade das turmas escolares varreram com intensidade as diferenças que são analisadas como fundamentais, atualmente, nas salas de aula e fora delas.

Percebe-se que as identidades fixas, acabadas, estão em crise (HALL, citado por MANTOAN, 2008) e a noção de identidades não fixas, voláteis é competente para desconstruir o sistema de significado excludente da escola atual. A diferença é, pois, o conceito que se impõe para que possamos defender a idéia de uma escola para todos, que esta escola passe a se tornar um espaço de inclusão (MANTOAN, 2008). Neste trabalho trataremos de trazer o conceito de surdocegueira e de possibilidades de ações que podem ser desenvolvidas para que alunos com esta deficiência possam ser incluídos na escola 
comum e a importância do atendimento educacional especializado como subsídio no processo de inclusão.

\section{METODOLOGIA.}

Para realização deste trabalho, escolhemos como metodologia a revisão de literatura que consiste em um processo de busca, análise e descrição de um corpo do conhecimento em busca de resposta a uma pergunta específica. Segundo Gil (2008), o estudo bibliográfico é elaborado a partir de materiais que já existem constituídos de livros, artigos científicos etc. As fontes utilizadas para pesquisa foram às seguintes:

a) Foram utilizados livros disponíveis na biblioteca do Centro Universitário que tratava da temática em questão;

b)Artigos científicos foram acessados na base de dados Scielo, publicados nos últimos anos e revistas e livros digitais.

Em seguida deu-se início a coleta de dados através de leitura do material selecionado e registro de informações que foram retiradas das fontes de informações selecionadas. As categorias emergidas dessa pesquisa foram analisadas a luz do referencial teórico da temática de estudo.

\section{RESULTADOS E DISCUSSÃO}

Para compreendermos o conceito do que seria a surdocegueira, recorremos a Lagati(1995), que afirma ser uma condição que proporciona outros problemas além daqueles determinados pela cegueira e pela surdez. O termo hifenizado sugere uma categoria que somaria os problemas da surdez e da cegueira. O vocábulo sem hífen indicaria uma diferença, uma categoria singular e o impacto da lesão dupla, é multiplicativo e não aditivo, segundo o autor.

Para Mazine (2011), Pode-se asseverar, sem desacerto, que as investigações sobre deficiências múltiplas tiveram início, em nosso país, na soleira do século XXI, quando o MEC publicou o "Programa de Capacitação de Recursos Humanos do Ensino Fundamental:

Deficiência Múltipla Vol. 1. Fascículos I" pela Secretaria de Educação Especial, em 2000. Mazine (2011) diz traz que pesquisas sobre Surdocegueira e Deficiências Sensoriais Múltiplas têm sido realizadas em universidades em Dissertações de Mestrado e compõem, além disso, um número bastante reduzido no Brasil, o que pode ser constatado durante esta investigação. 
A surdocegueira é descrita como uma deficiência singular e se apresenta em quatro divisões: sujeitos que eram deficientes visuais e se tornaram surdos; sujeitos que eram surdos e se tornaram deficientes visuais; sujeitos que se tornaram surdos e deficientes visuais em decorrência de patologias adquiridas ao longo de suas vidas ou acidentes; sujeitos que nasceram ou adquiriram precocemente e não tiveram a oportunidade de desenvolver a linguagem, nem capacidades comunicativas ou cognitivas nem embasamento conceptual a respeito do qual os capacitem a estabelecer uma concepção da realidade (MCINNES, 1999).

Em relação à aprendizagem, os sujeitos com surdocegueira evidenciam problemas em observar, compreender e imitar o comportamento de membros da família ou de outros que venha a entrar em contato, devido aos prejuízos visuais e auditivos apresentados (MCINNES, 1999).

Nesse sentido, as técnicas mão-sobre-mão são importantes ferramentas de intervenção para o estabelecimento de vínculo com os sujeitos surdocegos. O ambiente planejado e organizado adequadamente para inserção da pessoa com surdocegueira favorece a interação com pessoas e objetos. Isso a auxilia a realizar antecipações, obter pistas e escolher com quem quer estar e quais as atividades que deseja fazer (BOSCO e MAIA, 2010). No momento da ação de comunicação, o educador ou outro interlocutor tem o papel de:

- Antecipar o que vai acontecer ou o ponto em que vão ocorrer as atividades;

- Instigar os sujeitos para participarem e descobrirem o espaço;

- Confirmar com estes se estão decifrando as informações e a todo o momento informar o que acontece no espaço em que estão ocupando (BOSCO e MAIA, 2010).

Se uma comunicação efetiva não for constituída na puerícia, o sujeito pode ao adolescer, tornar-se alguém com condutas impróprias para se comunicar. Pode empregar, assim, às vezes de força física para poder expor que não quer alguma coisa, como, por exemplo: empurrar a pessoa ou retirar da mão de uma pessoa algo que deseja (BOSCO e MAIA, 2010).

Durante este trabalho de revisão literária, pode-se observar a importância do trabalho escolar no desenvolvimento de condutas aceitas socialmente, especialmente, na viabilização do atendimento educacional especializado aos sujeitos com necessidades educacionais especiais.

Vale ressaltar, também, o papel fundamental do educador enquanto sujeito de mediação entre as crianças surdocegas e o meio, bem como na ampliação dos contatos destas com a realidade (CADERNASCIMENTO E COSTA, 2003). 
Com relação ao educador comum na prática pedagógica inclusiva, este interessado em incluir, acolhe o educando que lhe chega como um sujeito real e singular tenha este ou não deficiências. Essa atitude se manifesta em escuta e olhar atentos sem pré-julgamentos ou prognósticos de desempenho, baseados em preconceitos e/ou procedimentos escolares excludentes. Além disso, para todo e qualquer educando, é necessário repensar o espaço da escola e da sala de aula, o que pressupõe a mobilidade dos educandos surdocegos(BOSCO e MAIA, 2010).

Além disso, os espaços sociais como escolares e sua organização precisam pensar a vontade de incluir, não só com edificação de rampas, banheiros acessíveis, sinalização e ampliação de corredores, mas com atitudes pedagógicas que estimulem a acessível movimentação de todos os educandos e, de maneira especial, dos sujeitos com deficiência (BOSCO e MAIA, 2010).

O pressuposto que influência mútua ativa entre os sujeitos dentro dos contextos sociais pelos quais eles recorrem é essencial para a aprendizagem e desenvolvimento destes, nos possibilita compreender que os espaços escolares comuns em um trabalho conjunto com os espaços atendimentos educacional especializado, caracterizado nas escolas pelas salas de multimeios, com profissionais educadores preparados para realizarem suas intervenções junto aos educandos com necessidades educativas especiais, contribuem para o desenvolvimento destes e para sua socialização.

Os intercâmbios ocorridos nas situações vivenciadas pelos sujeitos são concebidos por um espaço formado por princípios ou mecanismos articulado uns aos outros, que se interrelacionam e vão dos mais simples (casa, sala de aula), chamados microssistemas, aos mais complexos (cultura brasileira), os macrossistemas (BRONFENBRENNER, citado por GALVÃO e MIRANDA, 2013).

Bronfenbrenner (citado por Galvão e Miranda, 2013) assevera que consisti ao espaço escolar, após a família, ser este o que mais potencializa estados de desenvolvimento, visto que no espaço escolar, durante todo tempo, se estabelecem relações entre as crianças e seus pares, entre as crianças e os adultos, o que permite garantir que o ambiente proporcionado pela escola é um estrado produtivo para a promoção do desenvolvimento dos seres humanos.

Outro teórico que ajuíza sobre o valor do contexto social para a constituição da aprendizagem e consequente desenvolvimento das pessoas, em especial do sujeito com deficiência é Levy Vigotsky. Como pilar basal constitutivo de sua tese, ele afirma que o aprendizado dos sujeitos humanos implica um caráter social específico e um método através do qual os pequenos transpõem na existência intelectual dos que os rodeiam. As interações das crianças com os sujeitos de seu lugar desenvolvemIhe a fala interior, o pensamento reflexivo e o comportamento espontâneo (VIGOSTKY, 1997). Ele 
considera que o desenvolvimento psicológico dos sujeitos se realiza primeiramente no plano externo, interpsicológico, isto é, no contexto cultural das interações sociais como uma forma de adaptação social e em seguida delonga para o plano interno, intrapsicológico, como um meio de ajustamento individual (VIGOTSKY, 1997).

Nesse sentido, Vigotsky (citado por Galvão e Miranda, 2013), afirma que o agravamento da deficiência é aumentado ou diminuído a depender do papel social que a sociedade atribui à pessoa com deficiência. A deficiência, reconhecida na sua dimensão social, é uma constituição histórica, temporal, cotidiana, ressignificada em cada pequena ação, personificada e vivida nos grupos pelos quais as pessoas recorrem. Por isso, pode-se apreciar a escola como um respeitável lugar de significação social.

Partindo da ideia de compreender a escola como um lugar respeitável de significados sociais, entendemos que um plano de atendimento educacional especializado dentro do espaço escolar poderá contribuir para a socialização e desenvolvimento dos sujeitos com surdocegueira, sendo necessário que se desenvolva um diálogo do professor da Sala de Recursos e o professor de sala regular, como também de toda equipe e comunidade escolar para que em conjunto promovam as táticas e planos de ações para que exista o apropriado desenvolvimento e inclusão do educando na escola e na comunidade (GOMES et all,2007);

O educador do Atendimento educacional especializado - AEE tem como função basilar:

- Identificar e organizar recursos pedagógicos; elaborar e executar planos de ações para o atendimento dos alunos com necessidades especiais inseridos na sala de Recursos Multifuncionais - SRM das escolas públicas, visando complementar e ou suplementar a formação e a autonomia do aluno na escola e na sociedade para que este tenha um processo de aprendizagem satisfatório capaz de promover sua auto-estima, suas potencialidades cognitivas e afetivas (GOMES et all,2007);

- Este trabalho deverá ser desenvolvido em parceria com a família e os professores da sala regular em que o mesmo está matriculado, participando efetivamente da elaboração e execução do Projeto político Pedagógico- PPP da unidade escolar (GOMES et all, 2007).

Por meio de nossa investigação bibliográfica abarcamos o método de estudo de caso como uma solução primordial para a abertura de um planejamento bem organizado e fundamentado num estudo do sujeito com deficiência de surdogueira, para elaboração do atendimento Educacional Especializado. Este se apresenta como ferramenta imprescindível para o desenvolvimento do trabalho do educador o aproximando as dificuldades e através de estudointervenção, com membros envolvidos proporcionam assistência para laboração de disposições e táticas que propendem atenuar e/ou sanar 
dificuldades encontradas pelos sujeitos produzindo caminhos para a inclusão nos diversos espaços da sociedade.

\section{CONSIDERAÇÕES FINAIS.}

O presente estudo pretendeu fazer uma investigação sobre a inclusão de sujeitos com surdocegueira no âmbito do espaço da escola comum. Os resultados desta investigação nos possibilitam compreender que é possível a inclusão de pessoas com deficiência de surdocegueira no âmbito do espaço da escola comum e que esta se apresenta como lugar onde o desenvolvimento pode se alargar de forma satisfatória. Frisamos aqui a importância do diálogo entre os professores do espaço de sala de aula comum e da sala de atendimento educacional especializado (AEE). Enxergamos também no método de estudo de caso como uma ferramenta indispensável na elaboração do AEE, pois possibilita encontrar caminhos para a inclusão do sujeito surdocego. E para finalizar, acrescentamos que a utilização de atividades variadas, como brinquedos, jogos educativos e pátios ao ar livre são exemplos de atividades que podem ser parte do plano de $A E E$, contribuindo para o desenvolvimento da socialização e da aprendizagem. 


\section{REFERÊNCIAS.}

BOSCO, Ismênia Carolina Mota Gomes; MESQUITA, Sandra Regina S. Higino; MAIA, Shirley Rodrigues. A Educação Especial na Perspectiva da Inclusão Escolar: surdocegueira e deficiência múltipla. Brasília: Ministério da Educação. UFC-MEC.2010. V. 5. (COLEÇÃO a Educação Especial na Perspectiva da Inclusiva Escolar).

CADER-NASCIMENTO, Fátima Ali Abdalah Abdel; COSTA, Maria da Piedade Resende da. Mediação pedagógica no processo de desenvolvimento da comunicação em crianças surdocegas. Temas em Psicologia, v. 11, n. 2, p. 85-96, 2003.

GALVAO, Nelma de Cássia Silva Sandes and MIRANDA, Theresinha Guimarães. Atendimento educacional especializado para alunos com surdocegueira: um estudo de caso no espaço da escola regular. Rev. bras. educ. espec. [online]. 2013, vol.19, n.1, pp.43-60. ISSN 1413-6538. http://dx.doi.org/10.1590/S1413-65382013000100004.

GOMES, Adriana; FERNANDES, Anna; BATISTA, Cristina; SALUSTIANO, Dorivaldo; MANTOAN, Maria Teresa; FIGUEIREDO, Rita. Formação Continuada a Distância de Professores para o Atendimento Educacional Especializado Deficiência Mental. Secretaria de Educação Especial. 2007.

GIL, Antonio Carlos. Como elaborar projetos de pesquisa. 4. ed. São Paulo: Atlas, 2008.

LAGATI, S. Deaf-Blind or Deafblind International Perspectives on Terminology.1995 Tradução: Laura L. M.Anccilotto. São Paulo: Projeto Ahimsa/Hilton Perkins, 2002.

MANTOAN, Maria Teresa Eglér. Inclusão Escolar-caminhos e descaminhos, desafios, perspectivas. In: O desafio das diferenças nas escolas./ Maria Tereza Eglér Mantoan, (organizadora). - Petrópolis, Rj: Vozes, 2008.

MASINI, Elcie F. Salzano. Pesquisas sobre surdocegueira e deficiências sensoriais múltiplas. Constr. psicopedag., São Paulo , v. 19, n. 18, p. 65-72, 2011 . Disponível em

$<$ http://pepsic.bvsalud.org/scielo.php?script=sci_arttext\&pid=S141569542011000100007\&lng=pt\&n rm=iso>. acessos em 23 jun. 2016.

MCINNES, J. M. Deaf-blind infants and children: A development guide. Toronto, Ontario, Canada: University of Toronto Press, 1999.

ROPOLI, Edilene Aparecida et al. A educação especial na perspectiva da inclusão escolar: a escola comum inclusiva. Brasília: Ministério da Educação, v. 1, 2010.

SIERRA, Maria Angela Bassan. A humanização da pessoa surdocega pelo atendimento educacional: contribuições da Psicologia Histórico-cultural/ monografia: Maringá, 2010.

VYGOTSKY, L. S. Fundamentos de defectologia . VI. 5 Visor, Madrid, 1997. Educación, 1997. 


\section{Capítulo 3}

\section{doi $10.37423 / 211105004$}

\section{AS TECNOLOGIAS COMO APORTE PARA O PROCESSO DE ENSINO APRENDIZAGEM: UMA REVISÃO SISTEMÁTICA DA LITERATURA}

Alexandre Junior de Souza Menezes

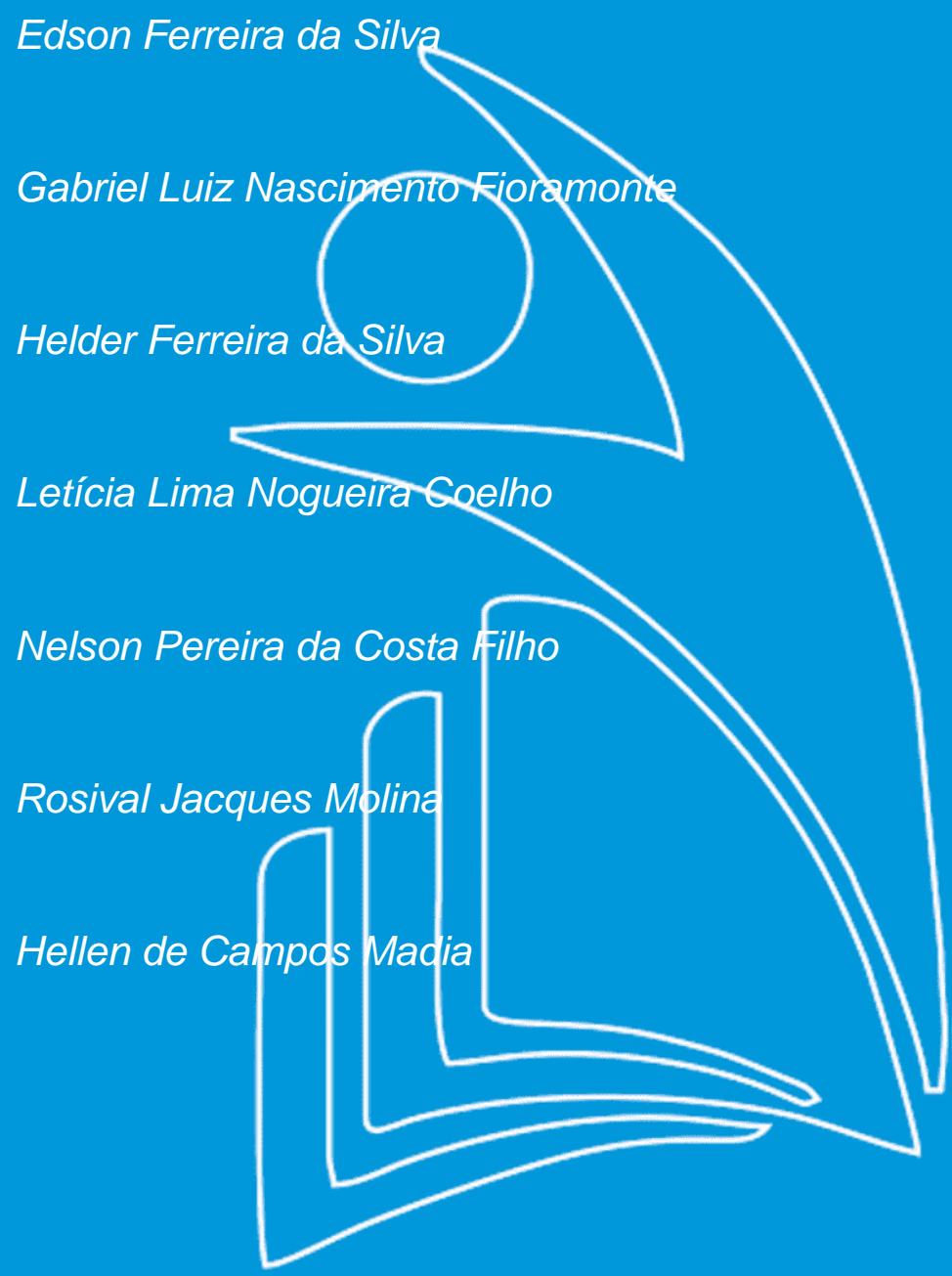

Universidade Federal do Vale do São

Francisco

Faculdade Fasol - faculdade solidária do oeste paulista - SP

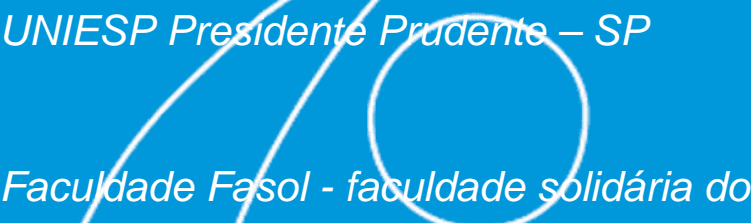
oesfe paulisfa - SP

Flaculdade Fasol - faculdade solidária do Ceste paulista - SP Universidade de Pernambuco

Faculdade fabol - facu/dade solidária do oeste padjista - SP

Facyldade Fasol - faculdade solidária do oeste paulista - SP

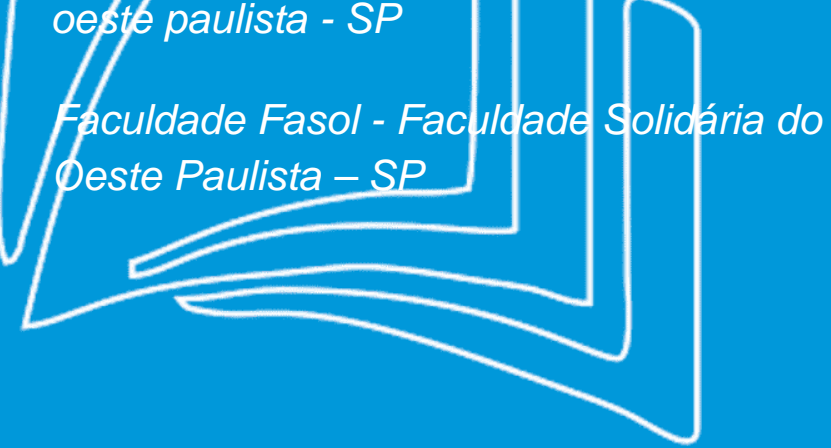


Resumo: O processo de ensino-aprendizagem por meio das Tecnologias da Informação e Comunicação - TIC, tem sido o foco dos pesquisadores educacionais. As práticas da sala de aula por meio da integração efetiva dessa tecnologia, representa um desafio para a comunidade escolar - equipe administrativa, professores, gestores e alunos. Assim, a fim de adentrar na compreensão deste fenômeno, propõe-se um estudo teórico e bibliográfico sobre a temática, que tem como objetivo compreender os fatores que influenciam o uso das TIC para tornar o ensino efetivo nas instituições de ensino e identificar as inovações que as TIC trouxeram no processo de ensino-aprendizagem, particularmente nas instituições de ensino de educação básica. Para atender aos objetivos, adotou-se uma metodologia de cunho qualitativa, por meio de uma abordagem bibliográfica/documental, para além disto, utilizou-se o banco de dados do portal de periódicos da CAPES, como lócus da investigação e os sujeitos, os artigos e obras considerados clássicos nacionais e internacionais sobre o tema, para isto foram realizadas várias buscas, onde pesquisou nos descritores do portal as palavras chaves com aspas, para delimitar e focar nos termos e alcançar um bom resultado, no final, foram 53 trabalhos selecionados e sistematizados, sendo estas obras, clássicos nacionais e internacionais, onde foram apresentado ao longo deste artigo. Os resultados deste estudo revelaram que os textos discorrem sobre diversas temáticas, principalmente sobre corpo docente e gestão.

Palavras-chaves: Tecnologias da Informação e Comunicação; Educação; Aprendizagem; Formação Continuada; Processos Educativos. 


\section{INTRODUÇÃO}

As Tecnologia da Informação e da Comunicação, também denominadas de TIC, são um meio eletrônico de captura, processamento, armazenamento e comunicação de informações. O uso das TIC na sala de aula, para os processos de ensino-aprendizagem são importantes, pois oferecem oportunidades para professores e alunos operarem, armazenarem, manipularem e recuperarem informações, encorajarem um aprendizado independente e ativo e se responsabilizar por aprender.

Um bom exemplo, podemos citar o ensino à distância - EaD, onde induz e motiva os professores e alunos a continuar usando estas ferramentas, para o aprendizado fora do horário

escolar, por meio de um planejamento que se encaixe na realidade e na dinâmica de cada indivíduo. Onde os atores deste processo, realizam e preparar lições e materiais, como a entrega do conteúdo do curso e facilitar o compartilhamento de recursos, conhecimentos e conselhos.

Este instrumento versátil tem a capacidade não apenas de envolver os alunos em atividades instrucionais para aumentar sua aprendizagem, mas também de ajudá-los a resolver problemas complexos para aprimorar suas habilidades cognitivas (JONASSEN e REEVES, 1996). Com base em Pernia (2008), argumenta que as TIC são usadas como tecnologias usadas para se comunicar, a fim de criar, gerenciar e distribuir informações. Ela acrescenta que uma ampla definição de TICs inclui computadores, internet, telefone, televisão, rádio e equipamento audiovisual. Ela explica ainda que as TIC são qualquer dispositivo e aplicativo usado para acessar, gerenciar, integrar, avaliar, criar e comunicar informações e conhecimentos.

A tecnologia digital está incluída nesta definição como serviços e aplicativos usados para funções de comunicação e processamento de informações associadas a esses dispositivos. Ainda neste contexto, Pernia (2008) explica ainda que as TIC são qualquer dispositivo e aplicativo usado para acessar, gerenciar, integrar, avaliar, criar e comunicar informações e conhecimentos. A tecnologia digital está incluída nesta definição como serviços e aplicativos usados para funções de comunicação e processamento de informações associadas a esses dispositivos. Ela explica ainda que as TIC são qualquer dispositivo e aplicativo usado para acessar, gerenciar, integrar, avaliar, criar e comunicar informações e conhecimentos.

A tecnologia digital está incluída nesta definição como serviços e aplicativos usados para funções de comunicação e processamento de informações associadas a esses dispositivos. Geralmente, três objetivos são distinguidos para o uso das TIC na educação (PLOMP, DEZ BRUMMELHIS e RAPMUD, 
1996): (i) O uso das TIC como objeto de estudo; refere-se ao aprendizado sobre TIC, que permite que os alunos usem TIC em sua vida diária. (ii) O uso das TIC como aspecto de disciplina ou profissão; refere-se ao desenvolvimento de habilidades em TIC para fins profissionais ou vocacionais. (iii) O uso das TIC como meio de ensino e aprendizagem; concentra-se no uso das TIC para melhorar o processo de ensino e aprendizagem (DRENT e MEELISSEN, 2007).

É fato que os professores estão no centro da mudança curricular e controlam o processo de ensino e aprendizagem. Portanto, eles devem ser capazes de preparar os jovens para a sociedade em que a competência para usar as TIC para adquirir e processar informações é muito importante (PLOMP, DEZ BRUMMELHIS e RAPMUD, 1996). Assim, este estudo teórico e bibliográfico, tem como objetivo compreender os fatores que influenciam o uso das TIC para tornar o ensino efetivo nas instituições de ensino e identificar as inovações que as TIC trouxeram no processo de ensino-aprendizagem, particularmente nas instituições de ensino de educação básica.

Para alcançar tais objetivos, este estudo constitui uma pesquisa qualitativa, que na ótica de Minayo (2001), esta perspectiva de pesquisa que está focada em elementos subjetivos do que elementos numéricos, que corresponde a um espaço mais profundo das relações, dos processos e dos fenômenos que não podem ser reduzidos à operacionalização de variáveis.

Para o desenvolvimento deste estudo, foi utilizado duas perspectivas de abordagem, sendo elas a pesquisa bibliográfica e a documental, que segundo o professor João José Saraiva da Fonseca, no livro metodologia da pesquisa científica, ele distingue e traça um paralelo, onde a, "A pesquisa bibliográfica é feita a partir do levantamento de referências teóricas já analisadas, e publicadas por meios escritos e eletrônicos, como livros, artigos científicos, páginas de web sites (FONSECA, 2002, p. 32). Por sua vez, a pesquisa documental, "[...] recorre a fontes mais diversificadas e dispersas, sem tratamento analítico, tais como: tabelas estatísticas, jornais, revistas, relatórios, documentos oficiais, cartas, filmes, fotografias, pinturas, tapeçarias, relatórios de empresas, vídeos de programas de televisão etc. (FONSECA, 2002, p. 32).

A ferramenta utilizada para o desenvolvimento da pesquisa, foi o levantamento bibliográfico "A pesquisa ou levantamento bibliográfico é um importante estágio na elaboração do quadro inicial, se o pesquisador utiliza teorias e conceitos para estudar fenômenos, a leitura é um hábito que deve ser cultivado." (DOXSEY \& DE RIZ, 2002-2003,p. 35), também conhecido como, revisão bibliográfica que, “Expor resumidamente as principais ideias já discutidas por outros autores que trataram do problema, levantando críticas e dúvidas, quando for o caso" (GERHARDT e SILVEIRA 2009, p.66). 
Para esta investigação, os artigos foram pesquisados e selecionados no banco de dados, se dá por meio de índices especializados que mantêm, para uma determinada área de conhecimento, um levantamento de artigos de muitos periódicos. Nos índices, os arquivos são indexados por palavraschave, autor, título e assunto, e incluem as referências dos que autores foram citados, e por quem, os resumos e/ou textos completos dos artigos (IDEM, 2009, p. 91). O banco escolhido para esta pesquisa foi o Portal de Periódicos da CAPES (Coordenação de Aperfeiçoamento de Pessoal de Nível Superior). Inclui também uma seleção de importantes fontes de informação acadêmica com acesso gratuito na Internet.

Assim, este artigo, estrutura-se inicialmente com o tópico introdutório, apresentando inicialmente a temática, seguindo do tópico referencial teórico, seguido da metodologia e por fim dos resultados e considerações finais.

\section{RESULTADOS DA REVISÃO}

A Educação e todo o universo que a compõe é permeado de uma série de desafios, dentre eles a interação entre a produção do saber e as mudanças aligeiradas ocorridas nos últimos tempos mediados pelo crescimento vertiginoso das tecnologias (LAU e SIM, 2008; NEWHOUSE, 2002). Existem expectativas muito grandes de que as Tecnologias da Informação e Comunicação possam interagir de maneira a proporcionar de maneira rápida soluções para a melhoria da qualidade da educação. Nesse aspecto ocorrem uma série de controvérsias construídas teoricamente ao longo dos últimos anos (PERNIA, 2008; GRIMUS, 2000).

Para Manuel Castells (2005), o que caracteriza a atual revolução tecnológica não é a centralidade de conhecimentos e informação, mas a aplicação desses conhecimentos e dessa informação para a geração de conhecimentos e de dispositivos de processamento/comunicação da informação, em um ciclo de realimentação cumulativo entre inovação e seu uso.

Assim as novas tecnologias da informação não são simplesmente ferramentas a serem aplicadas, mas processos a serem desenvolvidos. Usuários e criadores podem tornar-se a mesma coisa. Há uma relação direta entre os processos sociais de criação e manipulação de símbolos (a cultura da sociedade) e a capacidade de produzir e distribuir bens e serviços - às forças produtivas (RIFRIN, 2000; KOZMA, 1991, SCHANK, 2005). Pela primeira vez na história, a mente humana é uma força direta de produção, não apenas um elemento decisivo no sistema produtivo. 
E diferentemente, a revolução da tecnologia da informação difundiu-se pelo globo com a velocidade da luz em menos de duas décadas por uma lógica que é a aplicação imediata no próprio desenvolvimento da tecnologia gerada, conectando o mundo através da tecnologia da informação (CASTRO, 2003; ASSIS, 2013; BECTA, 2003). Segundo Castells, podemos pensar o paradigma tecnológico a partir de algumas características. Este novo paradigma aponta a um fenômeno na qual a informação é matéria-prima: são tecnologias para agir sobre a informação, não apenas informação para agir sobre a tecnologia, como foi o caso das revoluções tecnológicas anteriores (CASTELLS, 2005).

Estando conectados em rede não é possível fugir ou se distanciar de tais aspectos. o principal desafio está exatamente em promover a reflexão das informações circuladas em rede e a transformação do ambiente educativo mediado pelo uso das tecnologias em espaço de aprendizagens significativas e interligadas ao desenvolvimento tecnológico que faz parte do mundo globalizado atual (CAWTHERA, 2000; DRENT e MEELISSEM, 2007).

Para tanto vale considerar nesse debate que para se pensar o processo ensino e aprendizagem mediados pelo uso das tecnologias se fazem necessário caminhar por dois grandes eixos que incidem diretamente na efetivação de ações que incluem o uso das Tecnologia da Informação e Comunicação - TIC no ambiente das escolas, universidades, enfim, nos espaços de formação (ROGERS, 2003; WILLIAMS, 2003; GROFF e MOUZA, 2008, ROCHA, 2008). O primeiro é pensar a formação docente, seja ela inicial ou continuada e a inserção do uso das TIC nesse processo. O segundo e talvez, o desencadeador de muitas indagações, está localizado na ação pedagógica em que se utilizam as tecnologias.

Desta forma, a comunidade escolar se depara com três caminhos: repelir as tecnologias e tentar ficar fora do processo; apropriar-se da técnica e transformar a vida em uma corrida atrás do novo; ou apropriar-se dos processos, desenvolvendo habilidades que permitam o controle das tecnologias e de seus efeitos.

Consideramos a terceira opção como a que melhor viabiliza uma formação intelectual, emocional e corporal do cidadão, que lhe permita criar, planejar e interferir na sociedade. Pensamos na importância de um trabalho pedagógico em que o professor reflita sobre sua ação escolar e efetivamente elaborar e operacionalizar projetos educacionais com a inserção das tecnologias da informação e da comunicação - TIC - no processo educacional, buscando integrá-las à ação pedagógica na comunidade intra e extraescolar e explicitá-las claramente nas propostas educativas da escola (BRITO, 2006). 
Conforme Alberti (2005, p. 15), com relação à Educação, as transformações que necessitam ser realizadas consistem em passarmos de uma cultura escolar, centrada na concepção bancária, para uma mediada pelas tecnologias, com prática dialógica e problematizadora. Impulsiona-se, assim, o desenvolvimento da sociedade em rede de forma colaborativa. Para isso acontecer, alunos e professores não podem ser apenas espectadores das mudanças, eles precisam fazer parte delas, buscando compreender o que significam para a educação (OLIVEIRA, 2011; WILLIAMS, 2003, p. 23).

Compreendendo, principalmente, esse momento em que a escolarização está numa fase de transição, seja com a chegada de diferentes tecnologias que possibilitam melhorar nossas práticas, seja pela educação a distância que permite mais acesso à educação para diferentes pessoas e em diferentes lugares (BECTA, 2003; ROCHA, 2008).

Assim, no cenário atual o que se apresenta é o crescimento constante de ações que visam realizar a integração do uso das TIC no ambiente educacional mediados inclusive por investimentos de políticas públicas que deem conta de sanar as dificuldades operacionais para implementação das tecnologias no ambiente educativo. Vale destacar para estas questões a utilização de tablets e notebooks educativos como instrumentos pedagógicos (VOSGERAV e ROSSARI, 2012; WOODROW, 1992; AJAYI, 2009). Apesar de tais esforços ainda é visível o distanciamento da utilização de tais ferramentas como instrumento pedagógico, as aulas continuam ainda mediadas pelo modelo tradicional em que predomina o uso do livro didático e da lousa (SMARKOLA, 2007; MANUEL e CASTELLS, 2005; OLIVEIRA, 2011).

A constatação acima descrita é representada por questões inerentes ao processo formativo docente e a própria política institucional adotada pela escola, apesar de existirem experiências de escolas que adotam as TIC como eixo articulador para o desenvolvimento pedagógico, não é algo que se percebe na totalidade dos estabelecimentos de ensino. As TIC entram como eixo transversal e não como ferramenta pedagógica de integração do conhecimento e ação interdisciplinar.

Considerando então o disposto, vale trazer para este debate que o principal desafio e as discussões realizadas na contemporaneidade está na possibilidade de descentralização curricular para o desenvolvimento da aprendizagem mediados por mudanças curriculares, ou seja, se discute no âmbito das reformas curriculares a possibilidade inserção de uma carga horária não presencial, realizada por intermédio das TIC em formato de ambientes virtuais de aprendizagem - AVA (PARK, 2013; CAPE e WARD, 2002; GRIMUS, 2000). 
Nesse caso o professor teria um percentual de sua carga horária de forma presencial e as demais seriam a distância e este assumiria o papel de mediador do conhecimento pelo uso das tecnologias. É uma perspectiva que tem gerado muitos debates em torno da centralidade do papel do professor e da escola e ao mesmo tempo da supervalorização das TIC em detrimento a produção do conhecimento (DILLON e MORRIS, 1996; ERTMER, 2005, DELGADO, 2006).

Diante disso, um novo paradigma está surgindo na educação e o papel do professor, frente às novas tecnologias, será diferente (MORAN, 2007; SILVA, 2001; BRASIL, 2014; DELGADO, 2006). Com as novas tecnologias pode-se desenvolver um conjunto de atividades com interesse didático-pedagógico, como: intercâmbios de dados científicos e culturais de diversa natureza; produção de texto em língua estrangeira; elaboração de jornais interescolas, permitindo desenvolvimento de ambientes de aprendizagem centrados na atividade dos alunos, na importância da interação social e no desenvolvimento de um espírito de colaboração e de autonomia nos alunos (DANNEMAN, 2013; DANNEMAN, 2013).

O professor, neste contexto de mudança, precisa saber orientar os educandos sobre onde colher informação, como tratá-la e como utilizá-la. Esse educador será o encanador da autopromoção e o conselheiro da aprendizagem dos alunos, ora estimulando o trabalho individual, ora apoiando o trabalho de grupos reunidos por área de interesses (BASTON, 2011; MORAN, 2007).

A qualidade da educação, geralmente centrada nas inovações curriculares e didáticas, não pode se colocar à margem dos recursos disponíveis para levar adiante as reformas e inovações em matéria educativa, nem das formas de gestão que possibilitam sua implantação. A incorporação das novas tecnologias como conteúdos básicos comuns é um elemento que pode contribuir para uma maior vinculação entre os contextos de ensino e as culturas que se desenvolvem fora do âmbito escolar (MERCADO, 1998).

Vale destacar que dentre os aspectos acima citados encontra-se um elemento desafiador para o professor e que tem causado grandes polêmicas, o uso do celular em sala de aula, pois com o acesso facilitado a internet móvel, os jovens estudantes passam a conectar-se à rede de maneira rápida e permanente, todavia ao invés de ser utilizada como ferramenta de auxílio no processo educativo os professores e escolas passam a tomar medidas proibitivas que restringem o seu uso, o Estado de Pernambuco, por exemplo em algumas escolas se utilizam de legislação local que não permite o seu uso, o que amplia o debate e o distanciamento entre professores e alunos quando ao consenso para a inserção de determinadas tecnologias no ambiente educativo (BRASIL, 2014). 


\section{CONSIDERAÇÕES FINAIS}

Um dos fatores mais fortes entre as escolas no uso da tecnologia pelos professores é a pressão percebida para o uso da tecnologia (O'DWYER, RUSSELL e BEBELL, 2009; PARK, 2013). A pressão para usar a tecnologia indica que os professores sentem a expectativa dos outros de usar a tecnologia nas salas de aula. À medida que as tecnologias se desenvolvem, os professores continuam enfrentando uma pressão crescente para integrar a tecnologia em suas práticas de ensino (D'IMPERIO LIMA, 2013). Assim, é importante que os professores saibam lidar efetivamente com a pressão, porque o professor é a chave para integrar efetivamente a tecnologia nas salas de aula (FIRPO e PIERI, 2012). Pesquisadores como O'dwyer, Russell e Bebell (2009) e Russell, Bebell, O'dwyer e O'Connor (2003), descobriram que, quando os professores sentem pressão para usar a tecnologia, eles têm maior probabilidade de usá-la para fornecer instruções, para que seus alunos usem a tecnologia durante o horário das aulas, para criar produtos usando a tecnologia e para um grau menor, use a tecnologia para a preparação das aulas. No estudo de uso, suporte e efeito da tecnologia instrucional (IDEM, 2009), afirmam que a pressão percebida para usar a tecnologia está positivamente associada ao uso da tecnologia dos professores para fornecer instruções, criar produtos e preparar as aulas. Ao mesmo tempo, existem perspectivas críticas de pressão.

Com base nos resultados de Baston (2011), o autor insiste que, se os professores se sentem pressionados a mudar sua pedagogia para acomodar novas tecnologias, é mais provável que resistam a adotar completamente a tecnologia para criar produtos e para a preparação das aulas. Ao mesmo tempo, existem perspectivas críticas de pressão.

As características da tecnologia influenciam os processos de difusão de uma inovação e são fatores significativos que afetam uma adoção de inovação. As evidências sugerem que os atributos da inovação: vantagem relativa, compatibilidade, complexidade, experimentação e observabilidade, conforme percebidos pelos indivíduos, influenciam a taxa de adoção (SILVA, 2001). Ele enfatiza a necessidade de entender as percepções de uma inovação, pois isso tem forte influência na previsão futura de adoção de inovação específica.

Compreender as percepções de inovação dos educadores é essencial para a adoção bem-sucedida de tecnologia na aprendizagem, que de acordo com (NIEDERHAUSER e STODDART, 2001) é um tipo particular de inovação instrutiva. Complementando com o que os autores dizem, Rocha (2008) afirma que, quando os professores integram as TIC no ensino, eles operam como inovadores. 
Vários estudos recentes nessas áreas foram estudados. Os exemplos incluem estudos sobre as percepções dos alunos sobre tecnologia educacional no ensino superior (PARKER, BIANCHI e CHEAH, 2008), percepções de professores em formação, percepções de quadros de discussão assíncronos (ROCHA, 2008), percepções dos professores sobre tecnologias de aprendizagem (COPE e WARD, 2002) e atributos percebidos da Internet para prever a adoção da internet como ferramenta de aprendizado (OLIVEIRA, 2011).

Esses estudos encontraram observabilidade e experimentação como os dois elementos mais significativos. Além disso, estudo recente de Baston (2011), confirmou que a utilidade percebida e a facilidade de uso percebida foram preditores da aceitação do usuário pela tecnologia de computadores. Além disso, (LITWIN, 1997; ASSIS, 2013) relataram que vantagem relativa, complexidade, observabilidade e imagem são os fatores mais significativos na previsão das intenções dos alunos de fazer uso da tecnologia.

De acordo com Dillon e Morris (1996), Inovações que oferecem vantagens, compatibilidade com práticas e crenças existentes, baixa complexidade, possibilidade de avaliação e observabilidade terão uma taxa de integração mais ampla e rápida. Portanto, se os professores perceberem que uma inovação tem uma vantagem sobre a tecnologia existente, compatível com suas necessidades sociais, facilidade de adoção, ela pode ser experimentada antes do uso e, finalmente, os resultados podem ser vistos, é provável que os professores a adotem e integrem rapidamente.

O rápido crescimento das TIC trouxe mudanças notáveis no século XXI, além de afetar sua adoção e integração pelos professores no processo de ensino-aprendizagem (NASCIMENTO, 2007). A integração efetiva da tecnologia nas práticas da sala de aula representa um desafio para professores e administradores. Os resultados deste estudo indicam que professores e administradores têm um forte desejo de integrar as TIC na educação, mas encontram muitas barreiras. Portanto, essas descobertas têm implicações no treinamento dos professores para se tornarem usuários regulares das TIC, com foco na aquisição de habilidades básicas em TIC.

Para uma integração bem-sucedida das TIC no processo de ensino-aprendizagem, pode-se concluir que os fatores que influenciaram positivamente o uso de TIC por professores e administradores na educação incluem atitudes dos professores, competência em TIC, autoeficácia do computador, experiência de ensino, nível de ensino, desenvolvimento profissional, acessibilidade, suporte técnico, apoio à liderança, pressão para usar a tecnologia, política governamental sobre alfabetização em TIC e características tecnológicas (DANNEMAN, 2013). No entanto, a presença de todos os fatores 
aumenta a probabilidade de excelente integração das TIC no processo de ensino-aprendizagem. Portanto, a formação de professores nas questões pedagógicas deve ser aumentada para convencer os professores do valor do uso das TIC em seu processo de ensino-aprendizagem.

Enfim, não podemos ignorar a presença das TIC no espaço educativo e no processo de ensino e aprendizagem. Cabe então, ao professor o papel de estar engajado no processo, sensibilização e consciente não só das reais capacidades da tecnologia, mas das potencialidades e de suas restrições para que possa selecionar qual é a melhor utilização a ser utilizada num determinado assunto ou conteúdo, ajudando para a melhoria do ensino-aprendizagem, por meio de uma renovação das práticas pedagógicas e da transformação do aluno em protagonistas e sujeito ativo na construção do conhecimento, levando os, através da assimilação desta nova linguagem a inserirem-se na contemporaneidade. 


\section{REFERÊNCIAS BIBLIOGRÁFICAS}

AJAYI, L. "Uma exploração das percepções dos professores de pré-serviço de aprender a ensinar enquanto usam o quadro de discussão assíncrono". Sociedade e tecnologia educacional, vol.12, no. 2, 2009.

ASSIS, R. Escolas brasileiras e os portais do conhecimento. In: COMITÊ GESTOR DA INTERNET NO BRASIL - CGI.br. Pesquisa Sobre o Uso das Tecnologias de Informação e da Comunicação no Brasil TIC Educação 2012. Coord. Alexandre F. Barbosa. São Paulo: CGI.br, 2013.

BASTOS, M. I. Utilização das TIC em Escolas Públicas: um estudo de caso. Monitoramento e avaliação. Projeto 914 BRA 5002. Relatório Final, 2011.

BECTA. Uma revisão da literatura de pesquisa sobre barreiras à adoção de TIC pelos professores. 2003. Disponível em: http://partners.becta.org.uk/page_documents/research/barriers.pdf. [acessado em: 12/09/2019.

BRASIL. Lei no 12.965/2014. Marco Civil da Internet. Estabelece princípios, garantias, direitos e deveres para o uso da Internet no Brasil.

CASTRO, C. Educação na era da informação: promessas e frustrações, 2003. Disponível: http://www.iadb.org/sds/doc/Edu\&Tech2.pdf [acesso em 15/09/2019.

CAWTHERA, A, "Computadores em escolas secundárias em países em desenvolvimento: custos e outras questões", Departamento de Desenvolvimento Internacional, Links Mundiais para o Desenvolvimento e Rede de Desenvolvimento Humano do Banco Mundial, 2000.

COPE, C., \& WARD, P. "Integrando a tecnologia da aprendizagem nas salas de aula: a importância das percepções dos professores”. Revista Brasileira de Ciência do Solo, 5 (1), 67-74, 2002.

DELGADO, Omar Carrasco. Inserção e Mediações das Novas Tecnologias na Educação Básica. Vitória: Grafer, 2006.

DILLON, A., \& MORRIS, M. G "Aceitação pelo usuário de tecnologia da informação: teorias e modelos". Revista Anual de Ciência e Tecnologia da Informação, vol. 31, pp. 3-32, 1996.

DRENT, M \& MEELISSEN, M. "Quais fatores obstruem ou estimulam os educadores de professores a usar as TIC de maneira inovadora?”. Journal of Computers \& Education, (ARTIGO EM IMPRENSA), 2007.

ERTMER, P. A. "Crenças pedagógicas dos professores: a fronteira final em nossa busca pela integração tecnológica?" Pesquisa e desenvolvimento de tecnologia educacional, 53 (4), 25-39, 2005.

FIRPO, S.P.; DE PIERI, R.G. Avaliando os efeitos da introdução de computadores em escolas públicas brasileiras. Revista Brasileira de Inovação, v. 11, 2012.

GRIMUS, M. "TIC e multimídia na escola primária". Artigo apresentado na 16ạ conferência sobre usos educacionais das tecnologias da informação e comunicação, Pequim, China, 2000.

GROFF, J. \& MOUZA, C. "Uma estrutura para enfrentar os desafios do uso da tecnologia em sala de aula”. AACE Journal, vol. 16, n. 1, pp. 21-46, 2008. 
JONASSEN, D. H; REEVES, T. C. "Aprendendo com a tecnologia: usando computadores como ferramentas cognitivas". Em DH Jonassen (Ed.), Manual de pesquisa para comunicação e tecnologia educacional (pp. 693-719). Nova York: Simon e Schuster, 1996.

KOZMA, R. B. "Projetando e desenvolvendo software educacional eficaz": Lições dos vencedores do prêmio EDUCOM. Conferência Anual da EDUCOM, San Diego, CA, 1991.

LAU e SIM. "Explorando a extensão da adoção de TIC entre professores de escolas secundárias na Malásia". Revista Internacional de Computação e Pesquisa em TIC, vol. 2, n. 2, pp. 19-36, 2008 disponível em: http://www.ijcir.org/volume2 número2 / artigo 3.pdf. acessado em: 20/08/2019.

LITWIN, Edith (Org.) Tecnologia Educacional: política, histórias e propostas. Porto Alegre: Artes Médicas, 1997.

MORAN, José Manuel; MASETTO, Marcos T.; BEHRENS, Marilda Aparecida. Novas Tecnologias e Mediação Pedagógica. 13. ed. Campinas: Papirus, 2007.

NASCIMENTO, J. K. F. Histórico da Informática Educativa no Brasil. Unidade 1. Brasília: Universidade de Brasília, 2007.

NEWHOUSE, P. "O impacto das TIC na aprendizagem e ensino", Perth, Austrália Ocidental: Departamento de Educação, 2002.

NIEDERHAUSER, D. S \& STODDART, T. "Perspectivas instrucionais dos professores e uso de software educacional”. Ensino e formação de professores, vol. 17, pp.15-31, 2001.

O 'DWYER, L. M; RUSSELL, M; BEBELL, D. J. "Identificando características de professores, escolas e distritos associados ao uso da tecnologia por professores do ensino fundamental: uma perspectiva multinível”. Archives of Analysis Policy Archives, 12 (48), 2009.

OLIVEIRA. P. In: BONILLA; PRETTO (Org). Inclusão Digital: polêmica contemporânea. Salvador: EDUFBA, 2011.

PARK, J. et al. Uma Abordagem Sistemática para Facilitar a Integração Efetiva das TIC à Prática Pedagógica. In: COMITÊ GESTOR DA INTERNET NO BRASIL - CGI.br. Pesquisa Sobre o Uso das Tecnologias de Informação e da Comunicação no Brasil - TIC Educação 2012. Coord. Alexandre F. Barbosa. São Paulo: CGI.br, 2013.

PARKER, R. E, BIANCHI, A. E; CHEAH, T. Y. "Percepções da tecnologia instrucional: fatores sobre influência e consequências previstas". Educational Technology \& Society, vol. 11, n. 2, pp. 274-293, 2008.

PERNIA, E. E. Quadro estratégico para a promoção da alfabetização em TIC. 2008.

PLOMP, T. J; DEZ BRUMMELHIS, A. C. A; RAPMUND, R. “Ensinar e Aprender para o Futuro". Relatório da Comissão de Multimídia na Formação de Professores (COMMITT). Den Haag: SDU, 1996.

ROCHA, Sinara Socorro Duarte. O uso do Computador na Educação: a Informática Educativa. 2008. Revista Espaço Acadêmico, no 5, jun. 2008. 
ROGERS, E. M. "Difusão de inovações". Nova York: Free Press, 2003.

RUSSELL, M; BEBELL, D; O 'DWYER, L; O' CONNOR, K. "Examinando o uso da tecnologia do professor: implicações para preservice e na preparação do professor em serviço". Revista de Formação de Professores, vol. 54, n. 4, pp. 297-310, 2003.

SCHANK, R. C. "Lições de aprendizado, e Learning e treinamento: perspectivas e orientações para o instrutor esclarecido". São Francisco: Pfeiffer, 2005.

SILVA, Mozart Linhares da (Org.). Novas tecnologias: educação e sociedade na era da informação. Belo Horizonte: Autêntica, 2001.

SMARKOLA, C. "Preditores de aceitação de tecnologia entre professores alunos e professores experientes em sala de aula". Journal of Educational Computing Research, vol. 37, no.1, pp. 65-82, 2007.

VOSGERAU, D.S.R.; ROSSARI, M. Repensando o Projeto Político Pedagógico para a Integração das Tecnologias no Contexto Escolar. In: COMITÊ GESTOR DA INTERNET NO BRASIL - CGI.br.

Pesquisa Sobre o Uso das Tecnologias de Informação e da Comunicação no Brasil - TIC Educação 2012. Coord. Alexandre F. Barbosa. São Paulo: CGI.br, 2013.

WILLIAMS, M. D. "Integração tecnológica na educação. Em Tan, SC \& Wong, FL (Eds.), Ensino e Aprendizagem com Tecnologia”, pp. 17-31: Uma perspectiva da Ásia-Pacífico. Cingapura: Prentice Hall, 2003.

WOODROW, J. E. "A influência do treinamento em programação na alfabetização e nas atitudes dos professores de pré-serviço". Journal of Research on Computing in Education, vol. 25, n. 2,pp.200-219, 1992. 


\section{Capítulo 4}

\section{doi $10.37423 / 211105035$}

\section{ÁGUA E MEIO AMBIENTE NO ENSINO DE QUÍMICA: AS DIFICULDADES EM CONTEXTUALIZAR A TEORIA COM O COTIDIANO}

Edson Valente Chaves

Márcia Rebeca Silva de Oliveira

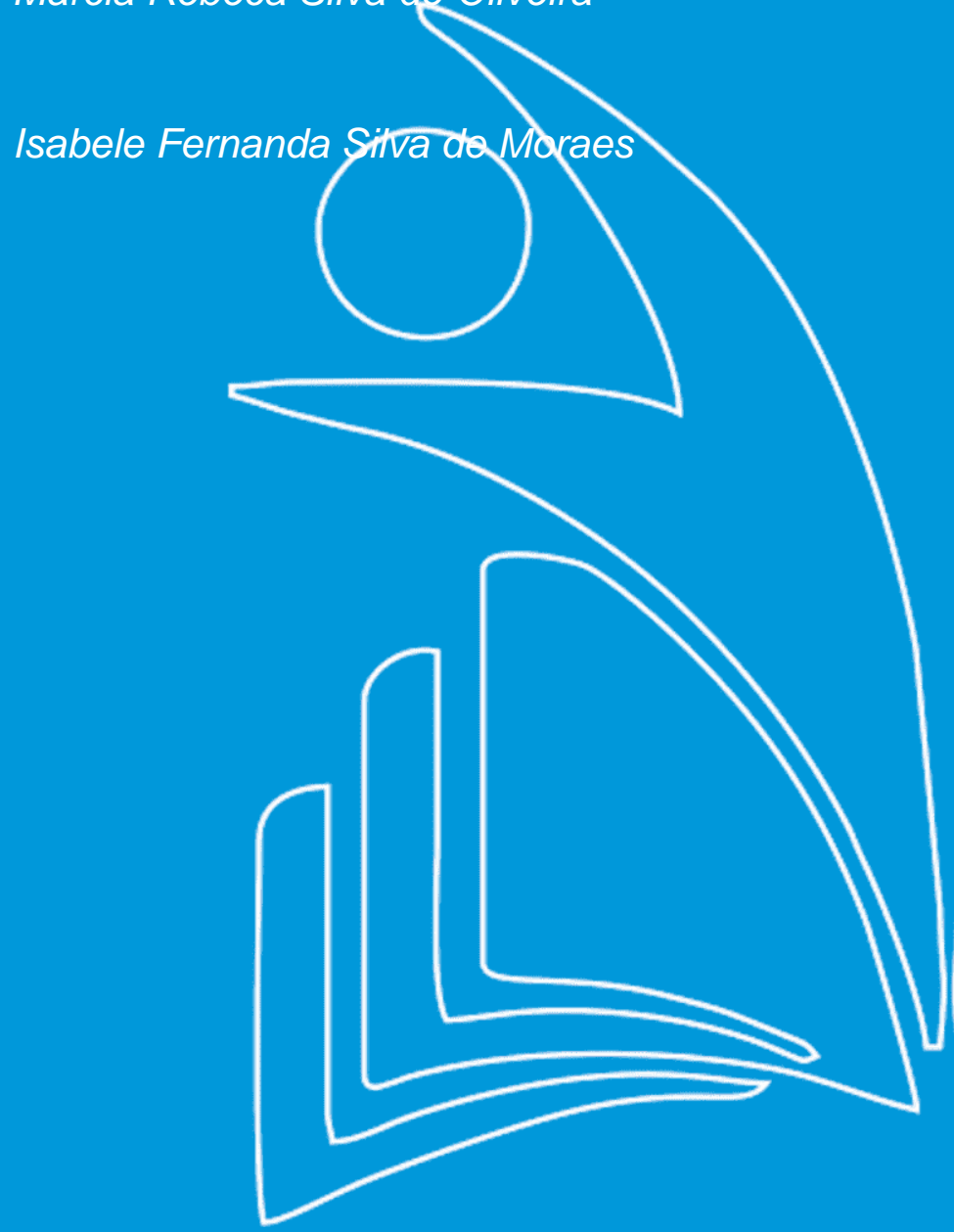

Instituto Federal de Educação, Ciência e

Tecnologia do Amazonas

Instituto Federal de Educação, Ciência e Tecnologia do Amazongs

Instituto Fedfral dé Educaçãa Ciência e Tecnologia do Aynazonas

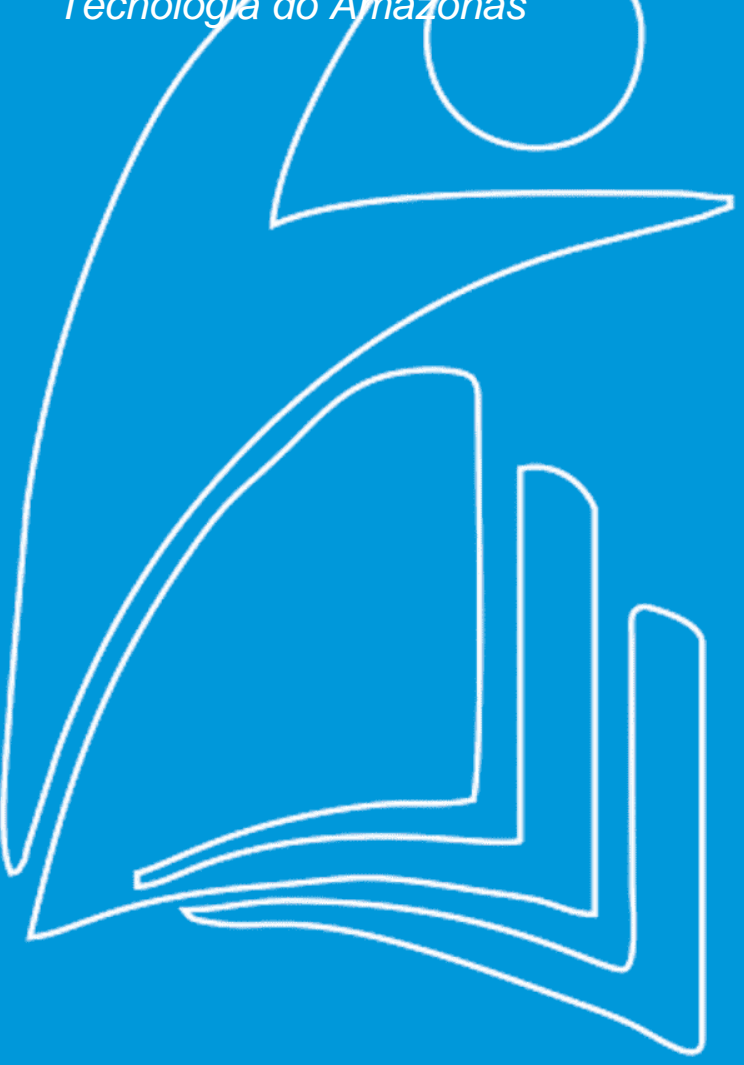


A Química é uma ciência que exerce influência direta na vida das pessoas, isso não significa que seja facilmente compreendida por todos, tendo em vista que boa parte do seu conteúdo envolve conceitos complexos e suas muitas especificações, que se apresentam de forma cumulativa, exigem um esforço tanto de professores quanto de alunos em conectar esse conteúdo com o dia a dia.

A aprendizagem no Ensino de Química tem como determinante a motivação dos alunos em estarem receptivos aos novos conteúdos. É comum, nas salas de professores e nos corredores das escolas, os relatos de alunos que não entendem o porquê de estudar Química, já que pouco percebem a sua relação com temas atuais. Uma relação que é pouco perceptível aos alunos, mesmo a Química sendo uma ciência da natureza e que estabelece relações com o mundo.

O papel do professor se torna desafiador neste cenário, de buscar processos e metodologias que contribuam para a motivação dos alunos em sala de aula. E como fazer isso quando se trabalha Ensino de Química e Meio Ambiente?

A relação com o meio ambiente é parte do cotidiano de todos, relacioná-lo com a sala de aula é trazer vivências do universo dos alunos, permitindo ao professor uma nova conexão entre a realidade e a abordagem conceitual conteudista. Essa conexão pode ser realizada em um espaço além da sala de aula, envolvendo Educação Ambiental e Ensino de Química, de modo a estimular a aprendizagem crítica.

Para que esta aprendizagem aconteça é necessário que o professor esteja disposto a agregar novas metodologias, buscando meios para estimular o aluno a associar novas e antigas informações, bem como correlacionar essas informações ao meio em que vive.

Desta forma seu ensino necessitará ser interdisciplinar e contextualizado para melhor compreensão dos alunos, mostrando que a correlação entre os saberes não pode ser evitada ou desprezada, valorizando o ensino para além do ensino de fórmulas e conceitos bem como contribuir para a formação cidadã e crítica do aluno:

“(...) a química é muito mais do que isto. É (...) ciência que recria a natureza, modifica-a e, com isso, o próprio homem. Como atividade criativa humana, está inserida em um meio social, atende a determinados interesses de grupos sociais e se insere nas relações de poder que perpassam a sociedade. Saber química é, também, saber posicionar-se criticamente frente a essas situações" (MALDANER, 1999, P. 03).

O ensino de Química, para além da educação formal, pode contribuir para o despertar da consciência social e ambiental das crianças e jovens, de modo que desenvolvam visão crítica em relação a evolução 
da ciência, tendo consciência do papel do homem na transformação e nas suas interações com a natureza.

\section{O ENSINO-APRENDIZAGEM NA QUÍMICA}

A aprendizagem é um processo que está presente em todo o desenvolvimento cognitivo do ser humano. É através do aprender que o indivíduo sabe como se comportar em sociedade, pois "ela capacita-o (...), leva o indivíduo a viver melhor ou pior, mas indubitavelmente a viver de acordo com o que aprende." (CAMPOS, 2003, p.14).

Desde a Antiguidade já se conceituava o processo de aprendizagem. Para Aristóteles, o conhecimento começa pelos sentidos e a partir deles se dá a aprendizagem, rejeitando a ideia de Sócrates de que o conhecimento preexiste no espírito do homem, sendo a aprendizagem o processo de despertar do conhecimento. Um misto de várias situações, sejam elas comportamentais ou biológicas, que levam ao processo de aprendizagem.

A criança, no início do seu desenvolvimento cognitivo começa a aprender por repetição e percepção do que está a sua volta e, a cada mudança biológica a capacidade de percepção aumenta, assim como de forma mais evidente se dá o processo de aprendizagem, visto que é mais facilmente observada a modificação no comportamento ao passo que a criança recebe novas informações.

A aprendizagem pode ser definida como uma modificação sistemática do comportamento, por efeito da prática ou experiência, com um sentido de progressiva adaptação ou ajustamento (CAMPOS, p. 30, 2003). É importante lembrar que no processo de aprendizagem deve ser levado em consideração as condições ambientais e orgânicas a que cada indivíduo está submetido. Dentro desse processo deve ser estudado o fator desempenho, visto que em virtude dele poderá, também, ser observada a ocorrência de aprendizagem.

A aprendizagem não é apenas a aquisição de conhecimento dos livros, como visto, ela está no processo de desenvolvimento cognitivo doa indivíduos, ela é também o modo pelo qual o indivíduo se ajusta aos moldes da sociedade em que vive. É um processo dinâmico e contínuo, pois está acontecendo incessantemente, é global, pois tem um amplo campo de trabalho, é pessoal, pois o processo acontece de forma única com cada indivíduo, é gradativo, pois acontece durante toda a vida e é cumulativo, pois o que foi aprendido não se perde com o passar dos anos. 
O aprender se apresenta como um processo de armazenamento de informações em conglomerados hierárquicos e que são incorporados a estrutura cognitiva do aluno de forma voluntária ou involuntária de acordo com o avançar dos níveis de ensino.

Com a observação, em sala de aula, o professor percebe vem a perceber a relação ensinoaprendizagem e, no caso do Ensino de Química, percebe-se a dificuldade que alguns alunos têm em compreender e relacionar os conteúdos com exemplos do conhecimento deles, fato proporcionado pela forma como os conteúdos são passados em sala de aula.

A Química é uma área do conhecimento multidisciplinar. Por este caráter, pode contribuir para a formação de cidadãos e expansão de visões de mundo e sociedade. Todavia esse caráter precisa ser uma realidade em sala de aula.

Observa-se o fato de que a Química é encarada como uma disciplina difícil, uma vez que tem um conteúdo vasto e com muitas especificações e que são apresentados aos alunos como um conjunto de conceitos e fórmulas, com pouca preocupação em trazer o conteúdo para perto deles, afastandoos da disciplina, tornando-a pouco interessante para os alunos. Ao trazer vivências e exemplificações do cotidiano, aproximando-os dos conteúdos conceituais, o professor traz um novo significado para a abordagem em sala de aula, aliado a abordagem conteudista, como defende Lisbôa:

A experimentação é um dos principais alicerces que sustentam a complexa rede conceitual que estrutura o ensino de química. Ele não é o único, uma vez que se encontra entrelaçado com outros, como o construído pela história da química e o construído pelo contexto sociocultural de que o estudante faz parte (LISBOA, 2015).

\section{O ENSINO E A QUÍMICA DO COTIDIANO NAS ÁGUAS}

Água, substância essencial para a vida, ditou a construção das civilizações, desde as mais remotas, passando pelas sociedades contemporâneas industriais. Era a presença de água um dos fatores determinantes para a instalação de acampamentos, reinos, cidades. Além da necessidade fisiológica do homem, ela compõe boa parte do corpo humano, ela é um recurso fundamental no desenvolvimento das sociedades.

A água é necessidade fundamental para o consumo diário individual e para o desenvolvimento da cadeia produtiva, pecuária, agricultura, indústria, incluindo navegação e geração de energia. Por isso é fundamental abordar a temática relacionando-a com o contexto do modelo de sociedade e desenvolvimento econômico. 
Desde os primeiros amazônidas, a água ditava o desenvolvimento das sociedades ao longo das margens do rio Amazonas. Em seu livro, História da Amazônia, Márcio Souza aponta como o cultivo de mandioca na várzea criou um rico suprimento de alimentos, e como os povos de terra firme exploravam ao máximo os recursos alimentícios dos rios e lagos, evidenciando o modo de vida dos povos da região, vinculada as águas.

Na capital do Amazonas não seria diferente. Manaus, banhada pelas águas da maior bacia hidrográfica do mundo, a Amazônica, tem seu relevo desenhado pelos lagos e igarapés, braços dos rios que circundam a cidade. São essas margens que a população utilizou para construção de moradias, assim como algumas das primeiras sociedades.

Contudo, devido ao crescimento da cidade e explosão demográfica, a população começou a ocupar essas áreas de forma desordenada, principalmente a partir do decreto que instalou a Zona Franca. Márcio Souza (2009) relata que a possibilidade de empregos atraiu uma população de migrantes, de multinacionais e comércios que transformaram a cidade num inferno com estrutura decadente, culminando com o surgimento das casas sobre as águas, falta de urbanização, precariedade de serviços públicos.

É nesse cenário que se constitui a problemática dos recursos hídricos e a necessidade de se abordar o ensino e a Química do cotidiano nas águas.

Neste contexto, transformar as margens de igarapés, entre eles podemos citar o igarapé do Quarenta em um ambiente de ensino, torna-se uma abordagem promissora de interdisciplinaridade referente ao Ensino de Química e Meio Ambiente para além das ilustrações, conceitos, fórmulas e exemplificações do cotidiano em sala de aula (Figura 1).

Figura1 - Igarapé do Quarenta.

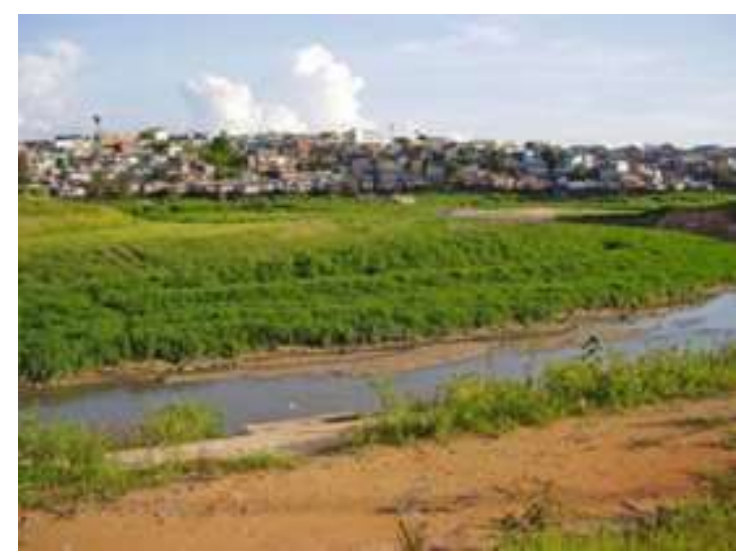

Fonte: Fonte Própria, 2018. 
O igarapé do Quarenta é uma das áreas com processo histórico de ocupação e intenso impacto ambiental ao longo dos anos. Impacto decorrente do modelo de desenvolvimento econômico adotado na cidade, com a instalação do Polo Industrial de Manaus (PIM) e o crescimento desordenado da cidade, como aponta Frota (2017), ao afirmar que a partir da interferência humana de forma inadequada nesses lugares, surgem problemas como a alteração nas águas dos igarapés, causada por lixo industriais e urbanos, lançado constantemente no seu leito poluindo-as e tornando-as imprestáveis para qualquer uso.

As águas sofrem os impactos da associação de industrialização e ação do homem, que culminam com a degradação que elas vêm sofrendo ao longo dos anos. Essa degradação pode ser evidenciada através do que define as normativas brasileiras referentes a qualidade da água. O Conselho Nacional do Meio Ambiente (CONAMA, 2005) estabelece o conceito de água ideal baseada em parâmetros físicoquímicos.

Todavia, esses parâmetros precisam ser analisados também a luz dos dados do ambiente natural das águas escuras, com características que acarretam um pH mais ácido (QUEIROZ et al, 2009), também pela presença de substâncias húmicas decorrentes da decomposição de matéria orgânica. sem ação do ambiente urbano. Essa análise visa permitir uma maior compreensão da ação antrópica ante os recursos naturais. Ou seja, o que está presente neste corpo d'água e que venha a ser considerados contaminantes comuns decorrentes da ausência de tratamento dos efluentes industriais e descarte de lixo e esgoto proveniente das ocupações as margens do igarapé, como corrobora Constantino et al:

Os metais podem ter origem litogênica, resultante de intemperismo ou de atividades antropogênicas, como o uso de fertilizantes, pesticidas, efluentes domésticos, indústria siderúrgica e/ou deposição atmosférica. Esses elementos podem ser classificados como essenciais e não tóxicos ( $\mathrm{Ca}$ e $\mathrm{Mg}$ ), essencial, mas tóxico em altas concentrações ( $\mathrm{Fe}, \mathrm{Mn}, \mathrm{Zn}, \mathrm{Cu}, \mathrm{Co}, \mathrm{Ni}$ e $\mathrm{Mo}$ ) ou tóxico $(\mathrm{Pb}, \mathrm{Hg}$ e Cd). Vários estudos de transporte de metais foram realizados na Amazônia. região, mas a maioria está centrada nos principais rios, principalmente os rios Negro, Solimões, Madeira e Amazonas (CONSTANTINO et al, 2019).

Uma das partes da Química é o Equilíbrio, que estuda as reações reversíveis e a velocidade das reações, sob temperatura constante. Dentro do estudo de Equilíbrio Químico, os parâmetros físico-químicos são parte do conteúdo, em especial o Potencial Hidrogeniônico $(\mathrm{pH})$. Ao estudar os parâmetros físicoquímicos da água, dentro do conteúdo Equilíbrio Químico, a partir de um ambiente não-formal, através das águas do igarapé do Quarenta, uma situação de impacto ambiental do cotidiano dos alunos, busca-se melhorar o processo de ensino-aprendizagem. Essa melhoria se dá ao sair do 
ambiente tradicional de ensino, com o emprego de atividades experimentais, como recurso pedagógico com finalidade de tornar as aulas mais dinâmicas, de modo que a abordagem conceitual na sala de aula seja realmente compreendida, através da reflexão da relação investigação científica e meio ambiente.

\section{PROPOSTAS METODOLÓGICAS PARA O ENSINO DE QUÍMICA E AS QUESTÕES AMBIENTAIS}

A aprendizagem de Química na educação básica possibilita ao aluno o entendimento dos processos e fenômenos químicos, além de contribuir para a construção do conhecimento científico. Dessa maneira, o aluno logo nos primeiros anos tem a possibilidade de relacionar os conceitos abordados com as aplicações da tecnologia e reflexão de problemas ambientais.

As competências gerais a serem desenvolvidas na área de Química e da Ciência dizem respeito aos domínios da representação e comunicação, envolvendo a leitura e interpretação de códigos, nomenclaturas e contextualização sociocultural, ou seja, a inserção do conhecimento disciplinar nos diferentes setores da sociedade, suas relações com os aspectos políticos, econômicos e sociais de cada época e com a tecnologia e cultura contemporâneas (PCN, 2018, P.85).

Em virtude da preocupação com as questões do meio ambiente, a educação ambiental está cada vez mais ganhando espaço nos documentos curriculares e consequentemente esse tema está sendo debatido e discutido de maneira mais frequente.

Com base nas mudanças que esse tema está vivenciando um número significativo de conceitos estão sendo construídos e reconstruídos. Podemos citar, uma temática muito importante como a água que por muito tempo já foi considerada um recurso infinito e esse pensamento de "água ilimitada" gerou danos irreparáveis ao planeta seja pelo desmatamento, falta de manejo adequado do solo entre outros (Figura 2). 
Figura 2 - Presença de lixo no leito do Igarapé do Quarenta.

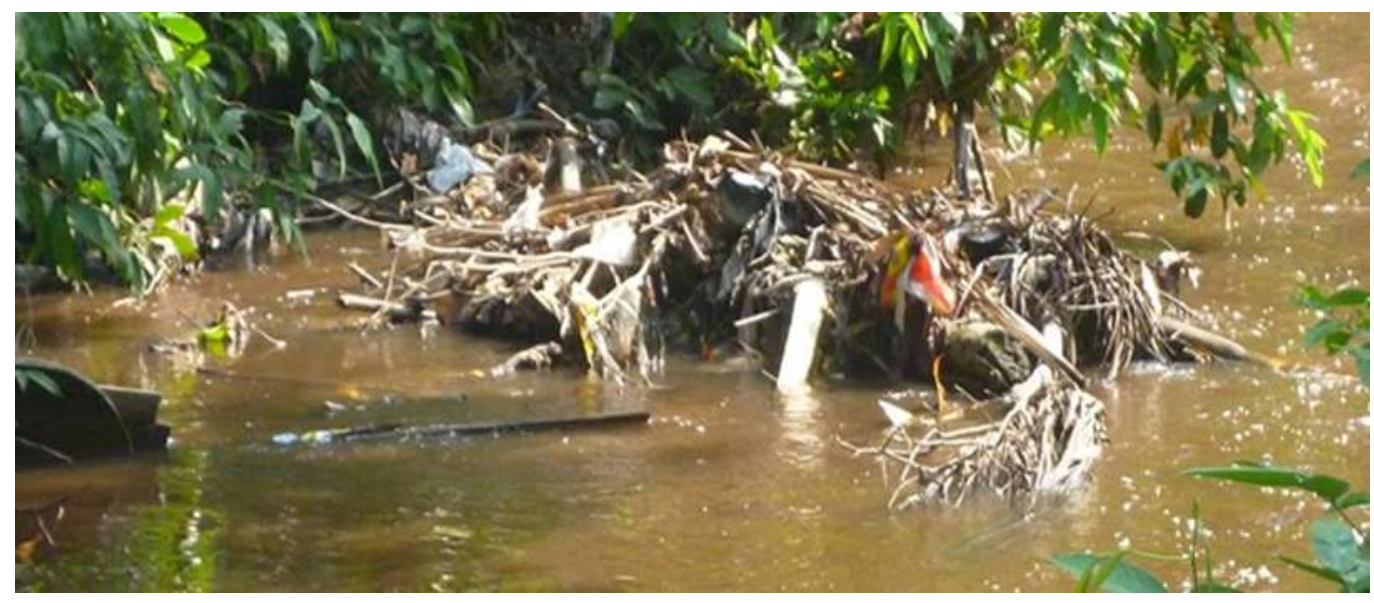

Fonte: Fonte Própria, 2018.

A escola tem um papel fundamental no processo de reflexão e desconstrução de ideias, é nesse espaço onde a pessoa recebe os conhecimentos no que diz respeito a essa natureza, que tais assuntos devem ser discutidos, colocando em cada um o desejo de cuidar da natureza, e desconstruir a visão antropocêntrica que afirma que o homem pode usufruir da natureza sem nenhuma cautela.

Nessa perspectiva os pensamentos de Ramos; Vasconcelos (2015, p 73) corroboram para reforçar a ideia que o ser humano explora exageradamente os recursos naturais e como consequências dessa prática o meio ambiente tem sofrido drasticamente com ações antrópicas, causadoras de sua degradação. Por conta desse cenário os autores afirmam que o ensino de Química e a Educação Ambiental podem ser veículos fundamentais para promover a minimização do desperdício de água por meio de estratégias pedagógicas centradas no tema.

Diante dessa perspectiva muitos trabalhos já foram publicados acerca do ensino de química relacionado à água, portanto serão apresentadas propostas de procedimentos metodológicos com essa temática. Os autores Ramos; Vasconcelos (2015, p.76) propuseram em seu trabalho a contextualização do assunto através de uma palestra interativa para abordar conceitos fundamentais referentes à água, sua importância e preservação. Juntamente com a aplicação do kit didático e de um simulador, feito a partir de materiais alternativos e reutilizados, de etapas de pré-alcalinização, coagulação, floculação e decantação.

O intuito do trabalho foi abordar conteúdos como suspensão, soluções, coloides, misturas, separação de misturas, dissolução, pH, coagulante, coagulação floculação, discutir questões ambientais referentes ao uso da água na atualidade, descobrir quais metodologias técnico-científicas estão 
envolvidas no tratamento da água, identificar quais as contribuições da educação em particular, a Educação Ambiental como relação aos cuidados com a água e a aplicação de atividades científicospedagógicas contextualizadas

Dessa forma, segundo os autores, foi usada a metodologia qualitativa e quantitativa para se analisar os resultados ao longo do processo e chegar à conclusão que a palestra interativa juntamente com a aplicação do kit didático auxiliaram para despertar um olhar reflexivo referente a água. Foi observado, também, um aumento no número de alunos que passaram a relacionar a Química com o tratamento de água e a qualidade da água com a saúde.

Em contrapartida, a autora Lima $(2018$, p.48) em seus trabalhos educacionais citou que houveram aulas expositivas dialogadas, no campo, práticas experimentais e aplicação de um jogo. As aulas expositivas dialogadas tiveram o objetivo de transmitir informação acerca dos recursos naturais com foco na água e suas características.

Nas aulas de campo os alunos foram deslocados para um Parque Municipal de Manaus a fim de identificar os problemas com os recursos naturais e realizar a coleta de água, conforme os parâmetros sugeridos por um roteiro. Em seguida foi realizado a prática experimental dessa água para averiguação da temperatura, $\mathrm{pH}$, análise microbiológica e turbidez. Para efeito de comparação foi realizado os mesmos procedimentos com a água do bebedouro da escola.

Por fim, foi aplicado um jogo de tabuleiro, confeccionado a partir de materiais de baixo custo, para verificar de formas mais dinâmicas os conhecimentos obtidos acerca dos temas meio ambientes e água.

Nos resultados, a autora ressalta que ao aplicar o questionário inicial, anterior aos procedimentos didáticos para os alunos, ela observou que nas respostas para a pergunta "na sua opinião, é importante se preocupar com a água?" Os alunos demonstraram a tendência da antropocêntrica utilitarista, em que o homem é o centro de tudo e os recursos naturais servem para lhe servir.

Contudo após toda a intervenção metodológica o resultado obtido foi outro. Conforme descrito no trabalho, os alunos se interessaram bastante pelas aulas práticas, chegando a perguntar da professora do por que não se faziam mais aulas desse jeito, houve preocupação com o meio ambiente e melhor compreensão dos temas abordados na aula expositiva dialogada por conta da aula de campo, pois dessa forma os alunos puderam fazer a relação da teoria e visualizar na prática. $O$ jogo didático auxiliou para firmar os conceitos aprendidos em todas as etapas dos procedimentos adotados nesta pesquisa. 
Carbonell (2002), explica que esse interesse dos alunos, se dá pelo fato, de que os espaços fora da sala de aula despertam a mente e a capacidade de aprender, esses espaços podem ser considerados estimulantes, e alinhados a uma reflexão crítica, pode se classificar como um potente cenário para a aprendizagem significativa. Porém, é necessário que além da experimentação "in situ", é preciso, antes de tudo uma fundamentação prévia, tendo em vista que a materialização da teoria é a principal função.

No trabalho de Arrigo; Alexandre; Assai (2018) os autores se dispuseram a realizar uma sequência didática que se dividiu em três momentos. No primeiro momento foi levantada a questão problematizadora "De que modo o descarte incorreto de pilhas e baterias têm se revelado nocivo ao ambiente"? E para respondê-la foram aplicados dois vídeos e uma atividade extraclasse. No segundo momento foi realizado o estudo sistemático acerca do assunto de pilhas, metais presente nas pilhas, reação de oxirredução, representação de uma célula eletroquímica e cálculo do potencial padrão de redução e houve a atividade experimental da montagem de uma pilha de Daniel feita pelos alunos além de exercícios de interpretação e compreensão dos conceitos, leitura, pesquisa e uma visita ao lixão da cidade. No terceiro momento foi a retomada da questão inicial dada nos primeiros momentos aos alunos e em seguida foi dado uma "charge" para esses alunos, com o intuito de fazê-los interpretála com base nos conhecimentos construído ao longo do desenvolvimento das aulas, apresentando soluções para os problemas ambientais ocasionados pelo descarte incorreto das pilhas e baterias.

Assim, segundo os autores, os resultados observados no final da sequência didática foram positivos, pois os alunos compreenderam a composição das pilhas e baterias, os efeitos causados à saúde humana e dos animais, além dos efeitos causados pelo descarte incorreto das pilhas e baterias. A metade da sala explicou de maneira mais elaborada, com base em conceitos científicos, sobre a problemática.

Podemos analisar que nos três trabalhos citados, o aluno é o fator principal no processo de construção do seu próprio conhecimento, quando este, ver, assiste e percebe que está diretamente inserido no contexto, sentisse como parte dele e toma consciência de suas atitudes e práticas sociais (CERVI e NEGRÃO, 2016).

Dessa forma, é de suma importância abordar os assuntos ambientais nas aulas de química para que as pessoas entendam a importância do meio ambiente e assim se tornem mais conscientes. A relação da Química e os problemas ambientais ensinados sob uma perspectiva mais interacionista podem colaborar significativamente para despertá-lo de uma sociedade mais comprometida e responsável 
com suas ações no mundo, contribuindo para sensibilização do aluno, para o problema da água no seu contexto social. 


\section{REFERÊNCIA}

ARRIGO, Viviane; ALEXANDRE, Mara Cristina Lalli; ASSAI, Natany Dayani de Souza. O ensino de química e a educação ambiental: uma proposta para trabalhar conteúdos de pilhas e baterias. Experiências em Ensino de Ciências, V.13, No.5. 2018.

BRASIL, Plano Nacional Comum. Ciências da Natureza, Matemática e suas Tecnologias, 2018.

BRASIL. Conselho Nacional de Meio Ambiente. Resolução CONAMA N 357, de 17 de março de 2005. <https://www.icmbio.gov.br/cepsul/images/stories/legislacao/Resolucao/2005/res_conama_357_20 05_classificacao_corpos_agua_rtfcda_altrd_res_393_2007_ 397_2008_410_2009_430_2011.pdf> Acesso em: 25/08/2020.

CAMPOS, Dinah M. de S. Psicologia da Aprendizagem. 33a edição. Petrópolis: Vozes, 2003.

CARBOLNELL, J.. A aventura de inovar: a mudança na escola. Porto Alegre: Artmed, 2002.

CERVI, F.O.; NEGRÃO, G.N. Educação Ambiental: Novas Metodologias para Prática Docente com alunos do ensino médio. Cadernos PDE, Unicentro, 2016.

CONSTANTINO, Isabela C. et al. Distribution of Metals in the Waters and Sediments of Rivers in Central Amazon Region, Brazil. J. Braz. Chem. Soc., São Paulo, v. 30, n. 9, p. 1906-1915, Sept. 2019. Disponível em:

<http://www.scielo.br/scielo.php?script=sci_arttext\&pid=S010350532019000901906\&lng=en\&nrm= iso >. Acesso em 30/09/2019. Epub Sep 16, 2019. http://dx.doi.org/10.21577/0103-5053.20190100.

FROTA, Karla Patricia Palmeira. Igarapé do Quarenta: A reprodução do espaço e seus agentes sociais. Somanlu: Revista de Estudos Amazônicos, [S.I.], v. 13, n. 2, dez. $2017 . \quad$ ISSN 2316-4123.

Disponível em: <http://periodicos.ufam.edu.br/somanlu/article/view/4018>. Acesso em: 01/09/ 2019. doi: https://doi.org/10.17563/somanlu.v13i2.4018

LIMA, Emily Silva dos Santos. Proposta didática para o ensino de meio ambiente e água na disciplina ciências naturais. Dissertação para o Mestrado Profissional em Ensino Tecnológico - Instituto Federal de educação, Ciência e Tecnologia do amazonas, 2018.

LISBÔA, Julio C. F. QNEsc e a Seção Experimentação no Ensino de Química. Quím. nova esc. - São PauloSP, BR. Vol. 37, № Especial 2, p. 198-202, Dezembro: 2015 . Disponível em <http://qnesc.sbq.org.br/online/qnesc37_especial_2/16-EEQ-100-15.pdf > Acesso em 01/10/2019.

MALDANER, Otavio Aloisio. A pesquisa como perspectiva de formação continuada do professor de química. Química Nova, v. 22, n. 2, p. 289-292, 1999. Disponível em: http://dx.doi.org/10.1590/S010040421999000200023 Acesso em: 23/11/2020]

QUEIROZ, Maria Mireide Andrade et al. Hidroquímica do rio Solimões na região entre Manacapuru e Alvarães: Amazonas-Brasil. Acta amazonica, v. 39, n. 4, p. 943-952, 2009. Disponível em: <https://www.scielo.br/pdf/aa/v39n4/v39n4a22.pdf> Acesso em: 07/08/2020.

RAMOS, Irene de Lacerda; VASCONCELOS, Tomás Noel Herrera. Prática pedagógica a partir da aplicação de atividades contextualizadas sobre o tratamento de água no ensino de química e educação ambiental. Revista de Ensino de ciências e Matemática- REnCIMA, v.6, n.3, p. 72-90, 2015.

SOUZA, Márcio. História da Amazônia. Manaus: Editora Valer, 2009. 